\title{
Importance of cytochrome oxidase subunit 1 in phylogeny reconstruction of various classes of subphylum vertebrata
}

\author{
Usman Hameed, Sunbal Khalid, Sundas Javed and Ghulam Mustafa* \\ Department of Biochemistry, Government College University Faisalabad-38000-Pakistan \\ *Corresponding author's email: gmustafa_uaf@yahoo.com \\ Citation \\ Usman Hameed, Sunbal Khalid, Sundas Javed and Ghulam Mustafa. Importance of cytochrome oxidase subunit \\ 1 in phylogeny reconstruction of various classes of subphylum vertebrata. Pure and Applied Biology. Vol. 9, \\ Issue 3, pp1995-2006. http://dx.doi.org/10.19045/bspab.2020.90213
}

\begin{tabular}{llll}
\hline \hline Received: 02/03/2020 & Revised: 30/05/2020 & Accepted: 03/06/2020 & Online First: 14/06/2020 \\
\hline \hline
\end{tabular}

\section{Abstract}

Classification of organisms on the basis of morphology and fossil records is not accurate therefore protein barcoding using Cytochrome $\mathrm{C}$ oxidase subunit 1 (COX1) is used to identify and classify different organisms. COX1 due to its presence in all the animals was selected in this study for phylogeny reconstruction. Classes of subphylum vertebrata including Amphibia, Reptillia, Chondrichthyes, Osteichthyes and Aves were examined. Total 60 homologous sequences were analyzed, ten from each mentioned class and one sequence was added as an out group. A maximum-likelihood (ML) tree was reconstructed which depicted many important results including evolutionary relationships among these classes. The reconstructed phylogenetic tree was clustered into five unique clades. The early divergence of monophyletic group of mammals was revealed by a separate branch from other classes of subphylum vertebrata. Homo sapiens were revealed to be closely related to common chimpanzee. The minimum mean distance was found among individual organisms of Aves group and maximum mean distance was found among organisms of Reptilia which revealed that Reptiles belong to a class of most diverged species. Similarly, the minimum average evolutionary divergence was exhibited between groups of amphibians and reptiles and maximum was found between groups of mammals and chondrichthyes. Cytochrome oxidase subunit 1 is a powerful system in reconstruction of phylogenetic relationships among various species.

Keywords: Cytochrome oxidase subunit 1; maximum-likelihood; mitochondrial DNA; phylogeny; vertebrata

\section{Introduction}

Cytochrome C oxidase subunit 1 (COX1) is involved in catalyzing the reduction of water into oxygen in eukaryotes. It is an enzyme complex comprising of 13 subunits in mammals. Three enzymes of this complex including COX1 are large and form the catalytic core of the enzyme complex and are encoded by mitochondrial DNA. The 10 smaller nuclear-encoded subunits are arranged around the perimeter of the core enzyme [1]. The enzyme is a transmembrane protein integrated into the inner membrane of mitochondria and its structure and functions have been extensively studied. COXI is the catalytic subunit of the enzyme and present in almost all eukaryotes and therefore the sequence of COX1 protein is extensively used in classification of different species and to find relationships among species.

DNA barcoding and morphology have been used extensively for the identification and classification of different organisms. DNA 
barcoding is an effective tool for species identification in various taxa. DNA and/or protein sequence based phylogeny is of greater use than morphology based phylogeny. The classification of species on the basis of morphology and DNA sequencing has been found different from exact known phylogeny $[2,3]$. Therefore, a new type of phylogeny is being used to categorize animals. This technique is known as protein barcoding in which protein sequences are used to identify and classify different organisms. For Protein barcoding, the protein sequence of mitochondrial cytochrome c oxidase subunit 1 has been extensively used as a marker.

Phylogenetic methods for comparative analysis of DNA and protein sequences are becoming ever more important with the rapid accumulation of molecular sequence data spearheaded by numerous genome projects [4, 5]. It is now common for phylogeny reconstruction to be conducted using large data sets involving hundreds or even thousands of genes and proteins. Similarly, phylogenetic methods are widely used to estimate the evolutionary rates of genes and proteins to detect footprints of natural selection, and the evolutionary information has been used to interpret genomic data [6]. For instance, evolutionary conservation indicating negative purifying selection and accelerated evolution driven by positive Darwinian selection have been employed to detect functionally significant regions of the genome [7].

The phylogenetic relationships among different classes of subphylum vertebrata have not been studied extensively yet. Therefore, in this study, Homo sapiens COX1 protein sequence was comparatively analyzed with different species of Amphibians, Reptillia, Chondrichthyes, Osteichthyes, Aves and Mammalia. Ten species of each class were chosen on the basis of high sequence identity percentage with Homo sapiens COX1 protein sequence. The phylogenetic tree reconstructed in this study would be used to check if a newly discovered organism belongs to any of the above mentioned 6 classes of subphylum vertebrata.

\section{Materials and methods}

To reconstruct a phylogenetic tree of organisms of different classes of subphylum vertebrata, following steps were followed:

\section{Retrieval of COX1 protein sequences}

The protein sequence of Homo sapiens cytochrome c oxidase subunit 1 was retrieved from UniProt (https://www.uniprot.org) in FASTA format. To undertake the phylogenetic analysis using COX1, the protein databases were systematically screened for COX1 sequences using BLASTp from National Centre for Biotechnology Information (NCBI) [8]. While searching the homologous sequences of query, the hits were restricted to the species of classes of subphylum vertebrata only. Based on high matching percentage, the sequences of ten organisms from each class (i.e. Amphibians, Reptillia, Chondrichthyes, Osteichthyes, Aves, Mammalia) were selected and retrieved. The protein sequence of COX1 from Hypsosinga pygmaea was also retrieved and used to root the tree.

\section{Phylogeny reconstruction}

The multiple sequence alignment of the inferred amino acid sequences was performed in MEGA5 [9]. The gap opening penalty was set to be 10 and multiple alignment gap extension penalty to be 4 . The gaps in multiple sequence alignment show historical insertions or deletions and their objective is to bring homologous sites into the alignment into the same columns. Quality of alignment might affect the quality of the phylogenetic tree. The maximum-likelihood method was used to infer the evolutionary history [10]. A bootstrap consensus tree was inferred from 100 replicates to represent the evolutionary history of the sequences analyzed [11]. The phylogram was reconstructed to scale with branch lengths in the same units as those of 
the evolutionary distances used. Poisson correction method was used to compute evolutionary distances [12] which were in the units of the number of amino acid substitutions per site.

\section{Statistical analysis}

The statistical analyses including overall average, mean diversity within subpopulations, mean diversity in entire population, mean interpopulational diversity, within mean group distance, between groups mean distance, coefficient of differentiation and net between group mean distances were calculated using MEGA5 [9]. The frequencies in percent of all amino acids of COX1 protein sequences were also checked.

\section{Results \\ Phylogenetic analysis}

A comparative sequence analysis was carried out among COXI protein sequences of $H$. sapiens and other species belonging to six different classes of subphylum vertebrata (Fig. 1). The consensus sequence is also shown in the alignment. The multiple sequence alignment was further used to reconstruct a phylogram. Fig. 2 is showing the phylogram in which all clades have been compressed to show overall evolutionary relationships among selected classes. Fig. 3 with expended clades of selected classes is showing evolutionary relationships among individual taxa of each class. The phylogram reconstructed in this study would be used to infer evolutionary relationships of selected organisms. This tree would also be used to check whether the novel organism belongs to any of the six classes used in the tree. The reliability of this tree was checked using the COX1 protein sequence of Hypsosinga pygmaea which belongs to the class Arachnida of phylum Arthropoda and used as an out group.

The phylogram has been resolved in six different clades and all the organisms appeared in their respective clades. The common ancestor of classes Amphibia and Reptilia in the phylogram is showing their close evolutionary relationships that were further confirmed by their average evolutionary divergence study (Table 2). Similarly, it has been exhibited from the phylogram that Chondrichthyes (cartilaginous fishes) and Osteichthyes (bony fishes) have close evolutionary relationships as both have been evolved from a common ancestor. The separate branch of Mammalia is showing their early evolutionary divergence from other classes of subphylum vertebrata. The phylogram is also showing that after the divergence of Mammalia, the class Aves was diverged from other classes. The monophyletic group of Mammalia is showing that Homo sapiens have closer evolutionary relationship with Pan troglodytes (i.e. common chimpanzee) than Gorilla gorilla gorilla although all three species have been evolved from a common ancestor.

The organisms were divided into six groups based on their monophyletic groups or clades. The value of overall average was found to be 0.088 . Mean diversity within subpopulations was equal to 0.037 and mean diversity in entire population was found to be 0.088. The mean interpopulational diversity was equal to 0.051. To estimate the proportion of interpopulational diversity the value of coefficient of differentiation was determined that was found to be 0.575 .

The mean distances within and between groups were also determined. The estimates of average evolutionary divergence over sequence pairs within groups are given in (Table 1) in which number of amino acid substitutions per site from averaging over all sequence pairs within each group is shown. Minimum mean distance was found among individual organisms of Aves group whereas maximum mean distance was found among organisms of Reptilia which is showing that Reptiles belong to a class of most diverged species.

The estimates of evolutionary divergence over sequence pairs between groups is given in Table 2 in which number of amino acid substitutions per site from averaging over all sequence pairs between groups are 
shown. It has been revealed from Table 2 that minimum average evolutionary divergence was found between groups Amphibians and Reptilia whereas maximum average evolutionary divergence was found between Mammalia and Chondrichthyes.

Similarly, the estimates of net evolutionary divergence between groups of sequences are given in (Table 3 ) in which number of amino acid substitutions per site from estimation of net average between groups of sequences is shown. It was found that minimum value for net mean distance was found between groups Amphibians and
Reptilia whereas maximum value for net mean distance was found between groups Mammalia and Chondrichthyes.

\section{Amino acid composition of COX1}

The amino acid composition was also determined and given in (Table 4). All frequencies have been given in percentage in the table. Leucine was found in highest percentage in all COX1 protein sequences in all organisms with average of 12.07. Similarly, cysteine was found in lowed percentage in all sequences with an average of 0.22 .
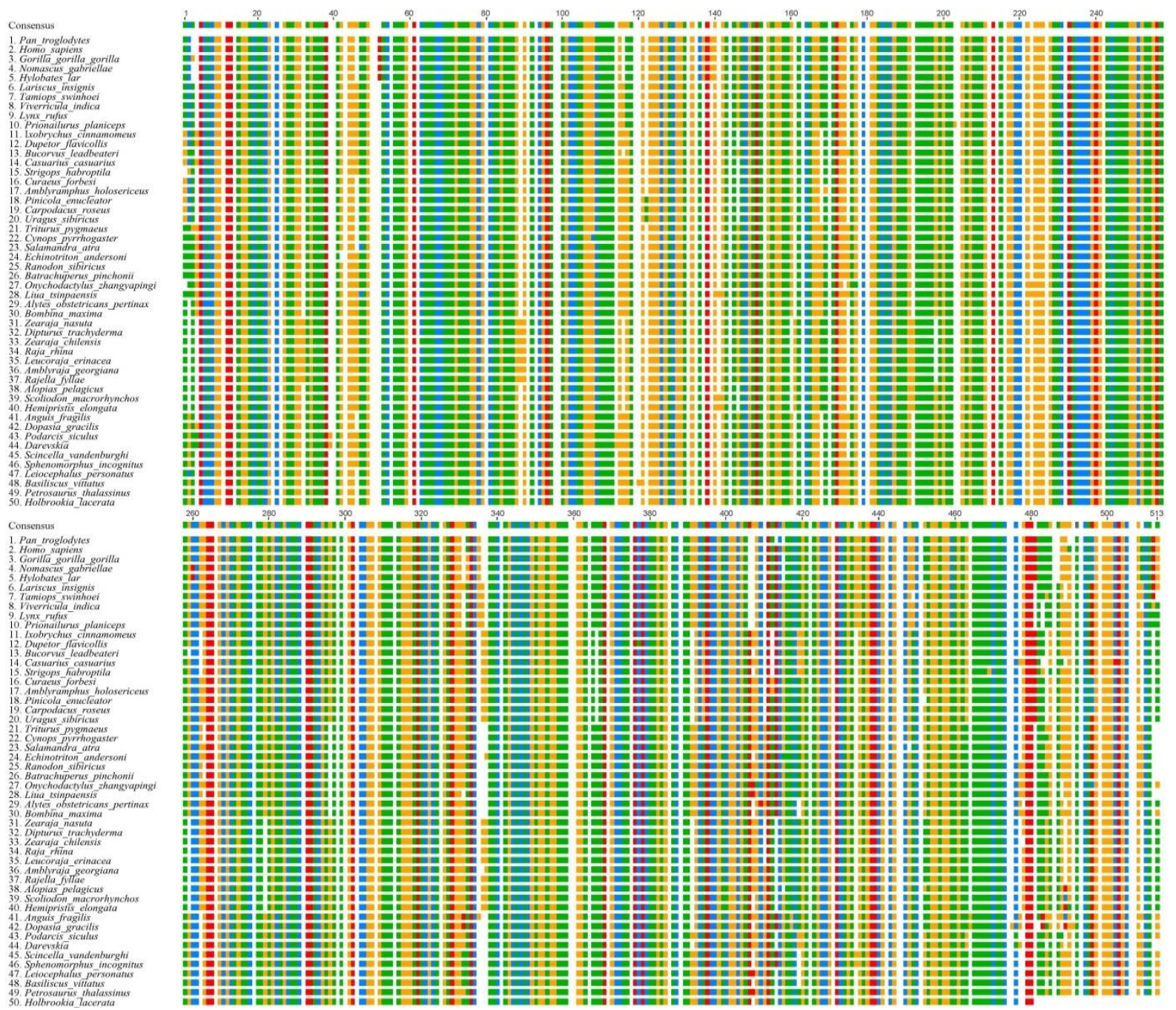

Figure 1. Multiple sequence alignment of COX1 protein sequences. Similar color bars are showing similar amino acids. Consensus sequence is also shown in the alignment. 


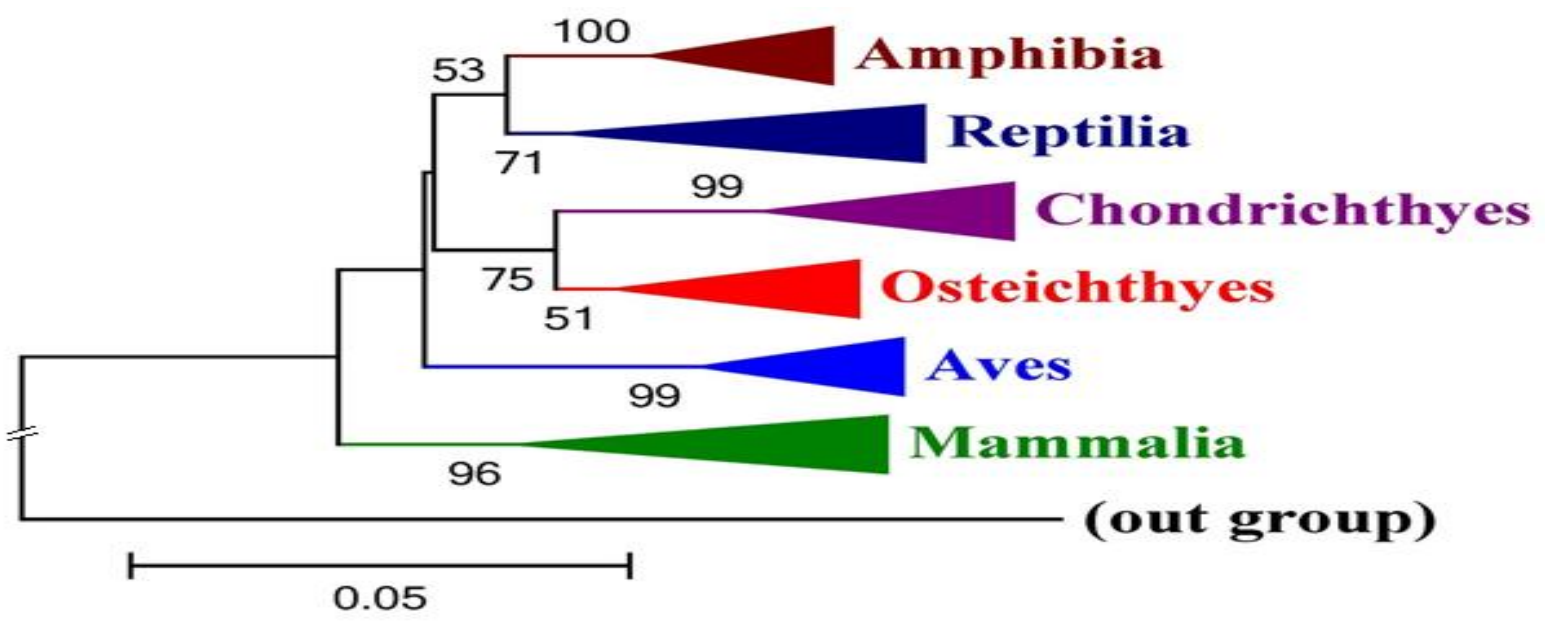

Figure 2. Compressed phylogram to show overall evolutionary relationships among selected classes of subphylum vertebrata. The tree was rooted with Hypsosinga pygmaea as an out-group. The scale bar is showing the time of divergence. The bootstrap values (100 replicates) are shown at the nodes

Table 1. Average evolutionary divergence within groups

\begin{tabular}{|c|c|c|}
\hline Sr. \# & Groups & Mean distance \\
\hline 1 & Mammalia & 0.039 \\
\hline 2 & Aves & 0.029 \\
\hline 3 & Amphibians & 0.031 \\
\hline 4 & Chondrichthyes & 0.030 \\
\hline 5 & Reptilia & 0.049 \\
\hline 6 & Osteichthyes & 0.047 \\
\hline
\end{tabular}

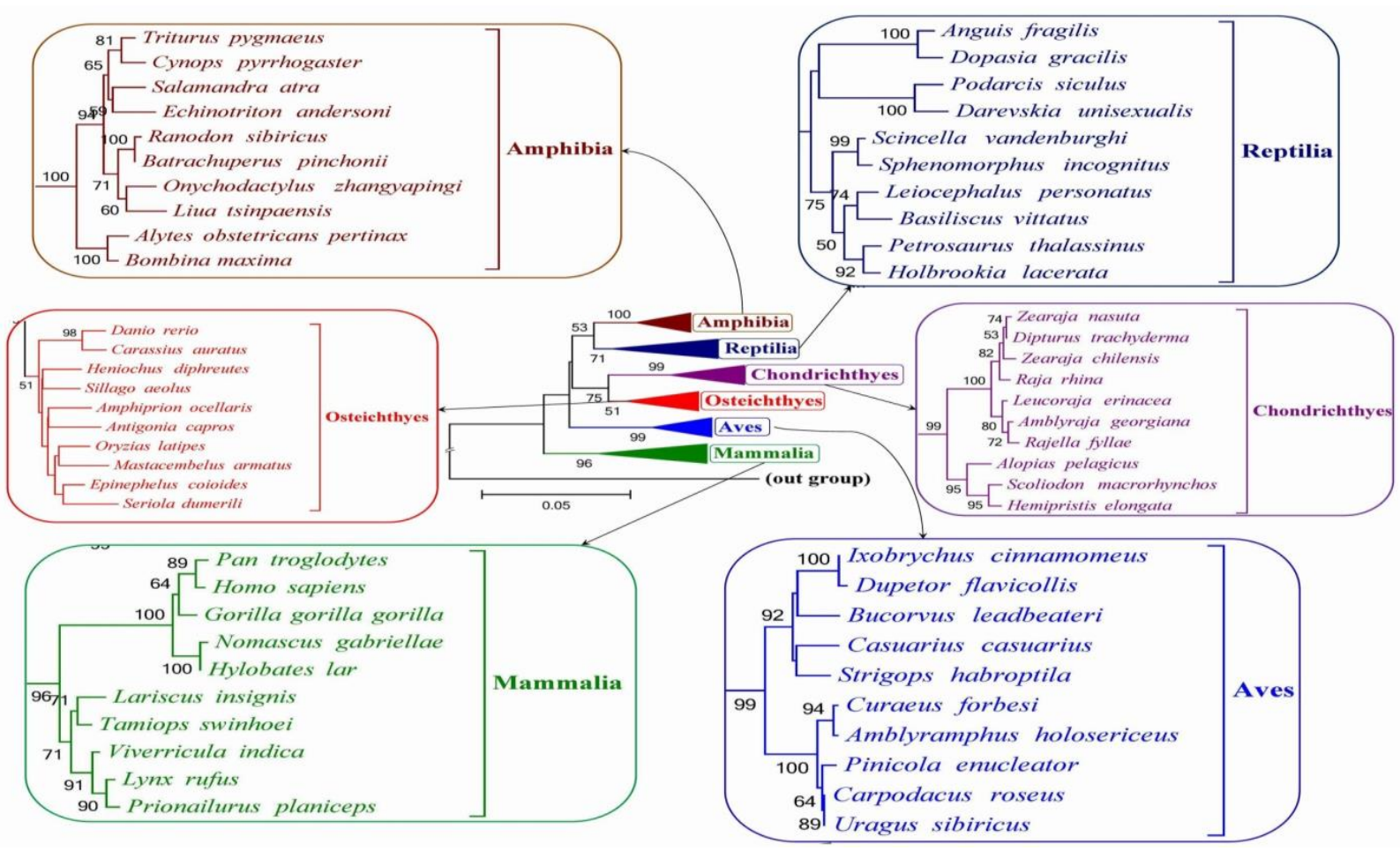

Figure 3. Molecular phylogeny of COX1 from organisms of subphylum vertebrata Distance and diversity analysis 
Table 2. Average evolutionary divergence between groups

\begin{tabular}{|c|c|c|c|c|c|c|c|}
\hline Sr.\# & Groups & Mammalia & Aves & Amphibians & Chondrichthyes & Reptilia & Osteichthyes \\
\hline 1 & Mammalia & -- & -- & -- & -- & -- & - \\
\hline 2 & Aves & 0.105 & -- & -- & -- & -- & - \\
\hline 3 & Amphibians & 0.103 & 0.096 & -- & -- & -- & - \\
\hline 4 & Chondrichthyes & $\mathbf{0 . 1 1 6}$ & 0.104 & 0.105 & -- & - & \\
\hline 5 & Reptilia & 0.095 & 0.094 & $\mathbf{0 . 0 7 4}$ & 0.109 & -- & - \\
\hline 6 & Osteichthyes & 0.110 & 0.096 & 0.085 & 0.079 & 0.087 & - \\
\hline
\end{tabular}

Table 3. Net mean distances between groups

\begin{tabular}{|c|c|c|c|c|c|c|c|}
\hline Sr.\# & Groups & Mammalia & Aves & Amphibians & Chondrichthyes & Reptilia & Osteichthyes \\
\hline 1 & Mammalia & -- & -- & -- & -- & -- & -- \\
\hline 2 & Aves & 0.071 & -- & -- & -- & -- \\
\hline 3 & Amphibians & 0.068 & 0.066 & -- & -- & -- \\
\hline 4 & Chondrichthyes & $\mathbf{0 . 0 8 2}$ & 0.075 & 0.075 & -- & -- \\
\hline 5 & Reptilia & 0.051 & 0.055 & $\mathbf{0 . 0 3 4}$ & 0.069 & -- & - \\
\hline & Osteichthyes & 0.067 & 0.058 & 0.046 & 0.040 & 0.039 & - \\
\hline
\end{tabular}

Table 4. Amino acid composition of cytochrome oxidase subunit 1 from selected species of subphylum vertebrata

\begin{tabular}{|c|c|c|c|c|c|c|c|c|c|c|c|c|c|c|c|c|c|c|c|c|c|}
\hline Name of plants & Ala & $\begin{array}{c}\mathrm{Cy} \\
\mathrm{s}\end{array}$ & $\begin{array}{c}\text { As } \\
\text { p }\end{array}$ & $\begin{array}{c}\text { Gl } \\
\mathbf{u}\end{array}$ & Phe & Gly & His & Ile & Lys & Leu & $\begin{array}{c}\mathrm{Me} \\
\mathrm{t}\end{array}$ & $\begin{array}{c}\text { As } \\
\text { n }\end{array}$ & Pro & Gln & $\begin{array}{c}\mathbf{A r} \\
\mathbf{g}\end{array}$ & Ser & $\begin{array}{c}\text { Th } \\
\mathbf{r}\end{array}$ & Val & $\begin{array}{c}\mathbf{T r} \\
\mathbf{p}\end{array}$ & Tyr & $\begin{array}{c}\text { Tota } \\
\text { l }\end{array}$ \\
\hline \multirow{2}{*}{ Pan troglodytes } & 8.1 & 0.1 & 2.9 & 1.9 & 7.9 & 8.9 & 3.3 & 7.2 & 1.9 & 12.0 & 6.0 & 3.3 & 5.6 & 1.3 & 1.5 & 6.2 & 6.4 & 7.2 & 3.1 & 4.2 & \\
\hline & 9 & 9 & 2 & 5 & 9 & 7 & 1 & 1 & 5 & 9 & 4 & 1 & 5 & 6 & 6 & 4 & 3 & 1 & 2 & 9 & 513 \\
\hline \multirow{2}{*}{ Homo sapiens } & 7.8 & 0.1 & 2.9 & 1.9 & 7.9 & 8.9 & 3.5 & 7.4 & 1.9 & 12.0 & 6.2 & 3.3 & 5.6 & 1.1 & 1.5 & 6.2 & 6.6 & 7.0 & 3.1 & 4.2 & \\
\hline & 0 & 9 & 2 & 5 & 9 & 7 & 1 & 1 & 5 & 9 & 4 & 1 & 5 & 7 & 6 & 4 & 3 & 2 & 2 & 9 & 513 \\
\hline \multirow{2}{*}{ Gorilla gorilla gorilla } & 7.8 & 0.1 & 2.9 & 1.9 & 8.1 & 8.9 & 3.5 & 7.8 & 1.9 & 11.8 & 6.0 & 3.3 & 5.6 & 1.1 & 1.5 & 6.2 & 7.0 & 6.4 & 3.1 & 4.2 & \\
\hline & 0 & 9 & 2 & 5 & $\begin{array}{c}0.1 \\
9\end{array}$ & 7 & 1 & 0 & 5 & 9 & 4 & 1 & 5 & 7 & 6 & $\begin{array}{c}0.2 \\
4\end{array}$ & 2 & 3 & 2 & $\begin{array}{c}7.2 \\
9\end{array}$ & 513 \\
\hline \multirow{2}{*}{ Nomascus gabriellae } & 7.9 & 0.1 & 3.1 & 1.7 & 8.1 & 8.9 & 3.7 & 7.0 & 1.9 & 11.8 & 5.8 & 3.1 & 5.8 & 1.3 & 1.5 & 6.2 & 6.6 & 7.4 & 3.1 & 4.0 & \\
\hline & 9 & 9 & 2 & 5 & 9 & 7 & 0 & 2 & 5 & 9 & 5 & 2 & 5 & 6 & 6 & 4 & 3 & 1 & 2 & 9 & 513 \\
\hline \multirow{2}{*}{ Hylobates lar } & 7.9 & 0.1 & 3.1 & 1.7 & 8.1 & 8.9 & 3.7 & 7.2 & 1.9 & 11.8 & 5.8 & 3.1 & 5.8 & 1.3 & 1.5 & 6.2 & 6.6 & 7.2 & 3.1 & 4.0 & \\
\hline & 9 & 9 & 2 & 5 & 9 & 7 & 0 & 1 & 5 & 9 & 5 & 2 & 5 & 6 & 6 & 4 & 3 & 1 & 2 & 9 & 513 \\
\hline \multirow{2}{*}{ Lariscus insignis } & 7.6 & 0.1 & 3.1 & 1.9 & 8.1 & 9.1 & 3.5 & 7.2 & 1.7 & 11.5 & 6.4 & 3.1 & 5.4 & 1.1 & 1.5 & 6.4 & 7.2 & 7.4 & 3.3 & 3.7 & \\
\hline & 0 & 9 & 2 & 5 & 9 & 6 & 1 & 1 & 5 & 0 & 3 & 2 & 6 & 7 & 6 & 3 & 1 & 1 & 1 & 0 & 513 \\
\hline \multirow{2}{*}{ Tamiops swinhoei } & 8.1 & 0.1 & 2.9 & 1.9 & 8.1 & 9.1 & 3.5 & 7.2 & 1.7 & 11.7 & 6.0 & 3.3 & 5.4 & 1.1 & 1.5 & 5.8 & 7.4 & 7.4 & 3.3 & 3.7 & \\
\hline & $\begin{array}{c}0.1 \\
9\end{array}$ & 9 & 2 & 5 & 9 & 6 & 1 & 1 & 5 & 0 & 4 & 1 & 6 & 7 & 6 & 5 & 1 & 1 & 1 & 0 & 513 \\
\hline
\end{tabular}


Pure Appl. Biol., 9(3): 1995-2006, September, 2020 http://dx.doi.org/10.19045/bspab.2020.90213

\begin{tabular}{|c|c|c|c|c|c|c|c|c|c|c|c|c|c|c|c|c|c|c|c|c|c|}
\hline Viverricula indica & $\begin{array}{c}7.9 \\
9\end{array}$ & $\begin{array}{c}0.1 \\
9\end{array}$ & $\begin{array}{c}2.9 \\
2\end{array}$ & $\begin{array}{c}1.9 \\
5\end{array}$ & $\begin{array}{c}8.1 \\
9\end{array}$ & $\begin{array}{c}9.1 \\
6\end{array}$ & $\begin{array}{c}3.5 \\
1\end{array}$ & $\begin{array}{c}7.4 \\
1\end{array}$ & $\begin{array}{c}1.5 \\
6\end{array}$ & $\begin{array}{c}11.7 \\
0\end{array}$ & $\begin{array}{c}6.4 \\
3\end{array}$ & $\begin{array}{c}3.3 \\
1\end{array}$ & $\begin{array}{c}5.4 \\
6\end{array}$ & $\begin{array}{c}1.1 \\
7\end{array}$ & $\begin{array}{c}1.5 \\
6\end{array}$ & $\begin{array}{c}6.0 \\
4\end{array}$ & $\begin{array}{c}7.4 \\
1\end{array}$ & $\begin{array}{c}7.0 \\
2\end{array}$ & $\begin{array}{c}3.3 \\
1\end{array}$ & $\begin{array}{c}3.7 \\
0\end{array}$ & 513 \\
\hline Lynx rufus & $\begin{array}{c}7.8 \\
0\end{array}$ & $\begin{array}{c}0.1 \\
9\end{array}$ & $\begin{array}{c}3.3 \\
1\end{array}$ & $\begin{array}{c}1.9 \\
5\end{array}$ & $\begin{array}{c}8.1 \\
9\end{array}$ & $\begin{array}{c}9.1 \\
6\end{array}$ & $\begin{array}{c}3.5 \\
1\end{array}$ & $\begin{array}{c}6.8 \\
2\end{array}$ & $\begin{array}{c}1.5 \\
6\end{array}$ & $\begin{array}{c}11.8 \\
9\end{array}$ & $\begin{array}{c}6.6 \\
3\end{array}$ & $\begin{array}{c}2.9 \\
2\end{array}$ & $\begin{array}{c}5.4 \\
6\end{array}$ & $\begin{array}{c}1.1 \\
7\end{array}$ & $\begin{array}{c}1.5 \\
6\end{array}$ & $\begin{array}{c}5.8 \\
5\end{array}$ & $\begin{array}{c}7.6 \\
0\end{array}$ & $\begin{array}{c}7.4 \\
1\end{array}$ & $\begin{array}{c}3.3 \\
1\end{array}$ & $\begin{array}{c}3.7 \\
0\end{array}$ & 513 \\
\hline Prionailurus planiceps & $\begin{array}{c}7.6 \\
0\end{array}$ & $\begin{array}{c}0.1 \\
9 \\
\end{array}$ & $\begin{array}{c}2.9 \\
2\end{array}$ & $\begin{array}{c}1.9 \\
5\end{array}$ & $\begin{array}{c}8.1 \\
9 \\
\end{array}$ & $\begin{array}{c}9.1 \\
6\end{array}$ & $\begin{array}{c}3.5 \\
1\end{array}$ & $\begin{array}{c}6.8 \\
2\end{array}$ & $\begin{array}{c}1.5 \\
6\end{array}$ & $\begin{array}{c}11.8 \\
9\end{array}$ & $\begin{array}{c}6.6 \\
3\end{array}$ & $\begin{array}{c}3.3 \\
1\end{array}$ & $\begin{array}{c}5.4 \\
6\end{array}$ & $\begin{array}{c}1.1 \\
7\end{array}$ & $\begin{array}{c}1.5 \\
6\end{array}$ & $\begin{array}{c}5.8 \\
5\end{array}$ & $\begin{array}{c}7.8 \\
0\end{array}$ & $\begin{array}{c}7.4 \\
1\end{array}$ & $\begin{array}{c}3.3 \\
1\end{array}$ & $\begin{array}{c}3.7 \\
0\end{array}$ & 513 \\
\hline Ixobrychus cinnamomeus & $\begin{array}{c}8.9 \\
7\end{array}$ & $\begin{array}{c}0.1 \\
9\end{array}$ & $\begin{array}{c}2.9 \\
2 \\
\end{array}$ & $\begin{array}{c}1.7 \\
5\end{array}$ & $\begin{array}{c}8.1 \\
9 \\
\end{array}$ & $\begin{array}{c}9.1 \\
6\end{array}$ & $\begin{array}{c}3.7 \\
0\end{array}$ & $\begin{array}{c}7.8 \\
0\end{array}$ & $\begin{array}{c}1.7 \\
5\end{array}$ & $\begin{array}{c}11.8 \\
9\end{array}$ & $\begin{array}{c}5.2 \\
6\end{array}$ & $\begin{array}{c}2.7 \\
3 \\
\end{array}$ & $\begin{array}{c}6.0 \\
4 \\
\end{array}$ & $\begin{array}{c}1.5 \\
6\end{array}$ & $\begin{array}{c}1.5 \\
6\end{array}$ & $\begin{array}{c}5.2 \\
6\end{array}$ & $\begin{array}{c}7.9 \\
9 \\
\end{array}$ & $\begin{array}{c}6.4 \\
3 \\
\end{array}$ & $\begin{array}{c}3.3 \\
1 \\
\end{array}$ & $\begin{array}{c}3.5 \\
1\end{array}$ & 513 \\
\hline Dupetor flavicollis & $\begin{array}{c}8.9 \\
7\end{array}$ & $\begin{array}{c}0.1 \\
9\end{array}$ & $\begin{array}{c}2.9 \\
2\end{array}$ & $\begin{array}{c}1.7 \\
5\end{array}$ & $\begin{array}{c}7.9 \\
9\end{array}$ & $\begin{array}{c}9.1 \\
6\end{array}$ & $\begin{array}{c}3.7 \\
0\end{array}$ & $\begin{array}{c}7.8 \\
0\end{array}$ & $\begin{array}{c}1.7 \\
5\end{array}$ & $\begin{array}{c}12.0 \\
9\end{array}$ & $\begin{array}{c}5.2 \\
6\end{array}$ & $\begin{array}{c}2.7 \\
3\end{array}$ & $\begin{array}{c}6.0 \\
4\end{array}$ & $\begin{array}{c}1.5 \\
6\end{array}$ & $\begin{array}{c}1.5 \\
6\end{array}$ & $\begin{array}{c}5.2 \\
6\end{array}$ & $\begin{array}{c}7.9 \\
9\end{array}$ & $\begin{array}{c}6.4 \\
3\end{array}$ & $\begin{array}{c}3.3 \\
1\end{array}$ & $\begin{array}{c}3.5 \\
1\end{array}$ & 513 \\
\hline Bucorvus leadbeateri & $\begin{array}{c}8.9 \\
7\end{array}$ & $\begin{array}{c}0.1 \\
9\end{array}$ & $\begin{array}{c}2.9 \\
2\end{array}$ & $\begin{array}{c}1.7 \\
5\end{array}$ & $\begin{array}{c}7.9 \\
9\end{array}$ & $\begin{array}{c}9.1 \\
6\end{array}$ & $\begin{array}{c}3.7 \\
0\end{array}$ & $\begin{array}{c}8.1 \\
9\end{array}$ & $\begin{array}{c}1.7 \\
5\end{array}$ & $\begin{array}{c}12.0 \\
9\end{array}$ & $\begin{array}{c}5.0 \\
7\end{array}$ & $\begin{array}{c}2.9 \\
2\end{array}$ & $\begin{array}{c}5.6 \\
5\end{array}$ & $\begin{array}{c}1.7 \\
5\end{array}$ & $\begin{array}{c}1.5 \\
6\end{array}$ & $\begin{array}{c}4.8 \\
7\end{array}$ & $\begin{array}{c}8.3 \\
8\end{array}$ & $\begin{array}{c}6.2 \\
4\end{array}$ & $\begin{array}{c}3.3 \\
1\end{array}$ & $\begin{array}{c}3.5 \\
1\end{array}$ & 513 \\
\hline Casuarius casuarius & $\begin{array}{c}9.1 \\
6 \\
\end{array}$ & $\begin{array}{c}0.1 \\
9 \\
\end{array}$ & $\begin{array}{c}2.9 \\
2 \\
\end{array}$ & $\begin{array}{c}1.7 \\
5 \\
\end{array}$ & $\begin{array}{c}7.9 \\
9 \\
\end{array}$ & $\begin{array}{c}9.1 \\
6 \\
\end{array}$ & $\begin{array}{c}3.9 \\
0 \\
\end{array}$ & $\begin{array}{c}7.9 \\
9 \\
\end{array}$ & $\begin{array}{c}1.7 \\
5 \\
\end{array}$ & $\begin{array}{c}12.0 \\
9 \\
\end{array}$ & $\begin{array}{c}4.6 \\
8 \\
\end{array}$ & $\begin{array}{c}2.7 \\
3 \\
\end{array}$ & $\begin{array}{c}6.0 \\
4 \\
\end{array}$ & $\begin{array}{c}1.5 \\
6 \\
\end{array}$ & $\begin{array}{c}1.5 \\
6 \\
\end{array}$ & $\begin{array}{c}5.0 \\
7 \\
\end{array}$ & $\begin{array}{c}7.9 \\
9 \\
\end{array}$ & $\begin{array}{c}6.6 \\
3 \\
\end{array}$ & $\begin{array}{c}3.3 \\
1 \\
\end{array}$ & $\begin{array}{c}3.5 \\
1 \\
\end{array}$ & 513 \\
\hline Strigops hab & $\begin{array}{c}8.9 \\
8 \\
\end{array}$ & $\begin{array}{c}0.2 \\
0 \\
\end{array}$ & $\begin{array}{c}2.9 \\
3 \\
\end{array}$ & $\begin{array}{c}1.7 \\
6 \\
\end{array}$ & $\begin{array}{c}8.0 \\
1 \\
\end{array}$ & $\begin{array}{c}9.1 \\
8 \\
\end{array}$ & $\begin{array}{c}3.7 \\
1 \\
\end{array}$ & $\begin{array}{c}7.8 \\
1 \\
\end{array}$ & $\begin{array}{c}1.7 \\
6 \\
\end{array}$ & $\begin{array}{c}12.5 \\
0 \\
\end{array}$ & $\begin{array}{c}4.6 \\
9 \\
\end{array}$ & $\begin{array}{c}2.9 \\
3 \\
\end{array}$ & $\begin{array}{c}5.6 \\
6 \\
\end{array}$ & $\begin{array}{c}1.7 \\
6 \\
\end{array}$ & $\begin{array}{c}1.5 \\
6 \\
\end{array}$ & $\begin{array}{c}5.4 \\
7 \\
\end{array}$ & $\begin{array}{c}8.0 \\
1 \\
\end{array}$ & $\begin{array}{c}6.2 \\
5 \\
\end{array}$ & $\begin{array}{c}3.3 \\
2 \\
\end{array}$ & $\begin{array}{c}3.5 \\
2 \\
\end{array}$ & 512 \\
\hline Curaeus forbesi & $\begin{array}{c}8.7 \\
7 \\
\end{array}$ & $\begin{array}{c}0.1 \\
9 \\
\end{array}$ & $\begin{array}{c}2.9 \\
2 \\
\end{array}$ & $\begin{array}{c}1.7 \\
5 \\
\end{array}$ & $\begin{array}{c}8.3 \\
8 \\
\end{array}$ & $\begin{array}{c}9.1 \\
6 \\
\end{array}$ & $\begin{array}{c}3.5 \\
1 \\
\end{array}$ & $\begin{array}{c}7.4 \\
1 \\
\end{array}$ & $\begin{array}{c}1.7 \\
5 \\
\end{array}$ & $\begin{array}{c}12.2 \\
8 \\
\end{array}$ & $\begin{array}{c}4.2 \\
9 \\
\end{array}$ & $\begin{array}{c}2.9 \\
2 \\
\end{array}$ & $\begin{array}{c}5.8 \\
5 \\
\end{array}$ & $\begin{array}{c}1.5 \\
6 \\
\end{array}$ & $\begin{array}{c}1.5 \\
6 \\
\end{array}$ & $\begin{array}{c}5.6 \\
5 \\
\end{array}$ & $\begin{array}{c}7.6 \\
0 \\
\end{array}$ & $\begin{array}{c}7.6 \\
0 \\
\end{array}$ & $\begin{array}{c}3.3 \\
1 \\
\end{array}$ & $\begin{array}{c}3.5 \\
1 \\
\end{array}$ & 513 \\
\hline $\begin{array}{c}\text { Amblyramphus } \\
\text { holosericeus }\end{array}$ & $\begin{array}{c}8.7 \\
7 \\
\end{array}$ & $\begin{array}{c}0.1 \\
9\end{array}$ & $\begin{array}{c}2.9 \\
2 \\
\end{array}$ & $\begin{array}{c}1.7 \\
5\end{array}$ & $\begin{array}{c}8.3 \\
8\end{array}$ & $\begin{array}{c}9.1 \\
6 \\
\end{array}$ & $\begin{array}{c}3.5 \\
1 \\
\end{array}$ & $\begin{array}{c}7.2 \\
1 \\
\end{array}$ & $\begin{array}{c}1.7 \\
5\end{array}$ & $\begin{array}{c}12.2 \\
8 \\
\end{array}$ & $\begin{array}{c}4.2 \\
9 \\
\end{array}$ & $\begin{array}{c}2.9 \\
2 \\
\end{array}$ & $\begin{array}{c}5.8 \\
5\end{array}$ & $\begin{array}{c}1.5 \\
6 \\
\end{array}$ & $\begin{array}{c}1.5 \\
6 \\
\end{array}$ & $\begin{array}{c}5.6 \\
5\end{array}$ & $\begin{array}{c}7.8 \\
0\end{array}$ & $\begin{array}{c}7.6 \\
0\end{array}$ & $\begin{array}{c}3.3 \\
1 \\
\end{array}$ & $\begin{array}{c}3.5 \\
1 \\
\end{array}$ & 513 \\
\hline Pinicola enucleator & $\begin{array}{c}8.7 \\
7 \\
\end{array}$ & $\begin{array}{c}0.1 \\
9\end{array}$ & $\begin{array}{c}2.9 \\
2 \\
\end{array}$ & $\begin{array}{c}1.7 \\
5\end{array}$ & $\begin{array}{c}8.3 \\
8\end{array}$ & $\begin{array}{c}9.1 \\
6\end{array}$ & $\begin{array}{c}3.5 \\
1\end{array}$ & $\begin{array}{c}7.6 \\
0\end{array}$ & $\begin{array}{c}1.7 \\
5\end{array}$ & $\begin{array}{c}12.2 \\
8 \\
\end{array}$ & $\begin{array}{c}4.2 \\
9\end{array}$ & $\begin{array}{c}2.9 \\
2 \\
\end{array}$ & $\begin{array}{c}5.8 \\
5\end{array}$ & $\begin{array}{c}1.5 \\
6\end{array}$ & $\begin{array}{c}1.5 \\
6\end{array}$ & $\begin{array}{c}5.6 \\
5\end{array}$ & $\begin{array}{c}7.2 \\
1 \\
\end{array}$ & $\begin{array}{c}7.8 \\
0\end{array}$ & $\begin{array}{c}3.3 \\
1\end{array}$ & $\begin{array}{c}3.5 \\
1\end{array}$ & 513 \\
\hline Carpodacus roseus & $\begin{array}{c}8.5 \\
8\end{array}$ & $\begin{array}{c}0.1 \\
9\end{array}$ & $\begin{array}{c}2.9 \\
2 \\
\end{array}$ & $\begin{array}{c}1.7 \\
5\end{array}$ & $\begin{array}{c}8.3 \\
8\end{array}$ & $\begin{array}{c}9.1 \\
6\end{array}$ & $\begin{array}{c}3.5 \\
1\end{array}$ & $\begin{array}{c}7.8 \\
0\end{array}$ & $\begin{array}{c}1.7 \\
5\end{array}$ & $\begin{array}{c}12.2 \\
8\end{array}$ & $\begin{array}{c}4.2 \\
9 \\
\end{array}$ & $\begin{array}{c}2.9 \\
2 \\
\end{array}$ & $\begin{array}{c}5.8 \\
5\end{array}$ & $\begin{array}{c}1.5 \\
6\end{array}$ & $\begin{array}{c}1.5 \\
6\end{array}$ & $\begin{array}{c}5.6 \\
5\end{array}$ & $\begin{array}{c}7.4 \\
1\end{array}$ & $\begin{array}{c}7.6 \\
0\end{array}$ & $\begin{array}{c}3.3 \\
1\end{array}$ & $\begin{array}{c}3.5 \\
1\end{array}$ & 513 \\
\hline Uragus sibiricus & $\begin{array}{c}8.5 \\
8\end{array}$ & $\begin{array}{c}0.1 \\
9\end{array}$ & $\begin{array}{c}2.9 \\
2\end{array}$ & $\begin{array}{c}1.7 \\
5\end{array}$ & $\begin{array}{c}8.3 \\
8\end{array}$ & $\begin{array}{c}9.1 \\
6\end{array}$ & $\begin{array}{c}3.7 \\
0\end{array}$ & $\begin{array}{c}7.8 \\
0\end{array}$ & $\begin{array}{c}1.7 \\
5\end{array}$ & $\begin{array}{c}12.2 \\
8\end{array}$ & $\begin{array}{c}4.2 \\
9\end{array}$ & $\begin{array}{c}2.9 \\
2\end{array}$ & $\begin{array}{c}5.8 \\
5\end{array}$ & $\begin{array}{c}1.5 \\
6\end{array}$ & $\begin{array}{c}1.5 \\
6\end{array}$ & $\begin{array}{c}5.6 \\
5\end{array}$ & $\begin{array}{c}7.4 \\
1\end{array}$ & $\begin{array}{c}7.6 \\
0\end{array}$ & $\begin{array}{c}3.3 \\
1\end{array}$ & $\begin{array}{c}3.3 \\
1\end{array}$ & 513 \\
\hline Triturus pygmaeus & $\begin{array}{c}8.1 \\
9 \\
\end{array}$ & $\begin{array}{c}0.1 \\
9 \\
\end{array}$ & $\begin{array}{c}2.9 \\
2 \\
\end{array}$ & $\begin{array}{c}1.9 \\
5 \\
\end{array}$ & $\begin{array}{c}7.8 \\
0 \\
\end{array}$ & $\begin{array}{c}8.9 \\
7 \\
\end{array}$ & $\begin{array}{c}3.7 \\
0 \\
\end{array}$ & $\begin{array}{c}7.4 \\
1 \\
\end{array}$ & $\begin{array}{c}1.5 \\
6 \\
\end{array}$ & $\begin{array}{c}11.8 \\
9 \\
\end{array}$ & $\begin{array}{c}6.0 \\
4 \\
\end{array}$ & $\begin{array}{c}2.9 \\
2 \\
\end{array}$ & $\begin{array}{c}5.4 \\
6 \\
\end{array}$ & $\begin{array}{c}1.3 \\
6 \\
\end{array}$ & $\begin{array}{c}1.5 \\
6 \\
\end{array}$ & $\begin{array}{c}6.6 \\
3 \\
\end{array}$ & $\begin{array}{c}7.4 \\
1 \\
\end{array}$ & $\begin{array}{c}7.2 \\
1 \\
\end{array}$ & $\begin{array}{c}3.3 \\
1 \\
\end{array}$ & $\begin{array}{c}3.5 \\
1 \\
\end{array}$ & 513 \\
\hline Cynops pyrrhogaster & $\begin{array}{c}8.1 \\
9 \\
\end{array}$ & $\begin{array}{c}0.1 \\
9\end{array}$ & $\begin{array}{c}2.9 \\
2 \\
\end{array}$ & $\begin{array}{c}1.9 \\
5\end{array}$ & $\begin{array}{c}7.8 \\
0\end{array}$ & $\begin{array}{c}8.9 \\
7 \\
\end{array}$ & $\begin{array}{c}3.7 \\
0\end{array}$ & $\begin{array}{c}7.4 \\
1 \\
\end{array}$ & $\begin{array}{c}1.5 \\
6\end{array}$ & $\begin{array}{c}11.8 \\
9\end{array}$ & $\begin{array}{c}6.2 \\
4 \\
\end{array}$ & $\begin{array}{c}2.9 \\
2 \\
\end{array}$ & $\begin{array}{c}5.6 \\
5\end{array}$ & $\begin{array}{c}1.3 \\
6\end{array}$ & $\begin{array}{c}1.5 \\
6\end{array}$ & $\begin{array}{c}6.2 \\
4 \\
\end{array}$ & $\begin{array}{c}7.0 \\
2 \\
\end{array}$ & $\begin{array}{c}7.6 \\
0\end{array}$ & $\begin{array}{c}3.3 \\
1 \\
\end{array}$ & $\begin{array}{c}3.5 \\
1\end{array}$ & 513 \\
\hline Salamandra atra & $\begin{array}{c}8.1 \\
9 \\
\end{array}$ & $\begin{array}{c}0.1 \\
9\end{array}$ & $\begin{array}{c}2.9 \\
2\end{array}$ & $\begin{array}{c}1.9 \\
5\end{array}$ & $\begin{array}{c}7.9 \\
9 \\
\end{array}$ & $\begin{array}{c}8.9 \\
7 \\
\end{array}$ & $\begin{array}{c}3.7 \\
0\end{array}$ & $\begin{array}{c}7.8 \\
0\end{array}$ & $\begin{array}{c}1.5 \\
6\end{array}$ & $\begin{array}{c}11.5 \\
0\end{array}$ & $\begin{array}{c}6.2 \\
4 \\
\end{array}$ & $\begin{array}{c}2.9 \\
2\end{array}$ & $\begin{array}{c}5.2 \\
6\end{array}$ & $\begin{array}{c}1.3 \\
6\end{array}$ & $\begin{array}{c}1.5 \\
6\end{array}$ & $\begin{array}{c}6.8 \\
2\end{array}$ & $\begin{array}{c}7.2 \\
1 \\
\end{array}$ & $\begin{array}{c}7.0 \\
2 \\
\end{array}$ & $\begin{array}{c}3.3 \\
1\end{array}$ & $\begin{array}{c}3.5 \\
1\end{array}$ & 513 \\
\hline Echinotriton andersoni & $\begin{array}{c}7.6 \\
0 \\
\end{array}$ & $\begin{array}{c}0.1 \\
9 \\
\end{array}$ & $\begin{array}{c}2.9 \\
2 \\
\end{array}$ & $\begin{array}{c}1.9 \\
5 \\
\end{array}$ & $\begin{array}{c}7.9 \\
9 \\
\end{array}$ & $\begin{array}{c}8.7 \\
7 \\
\end{array}$ & $\begin{array}{c}3.7 \\
0 \\
\end{array}$ & $\begin{array}{c}7.9 \\
9 \\
\end{array}$ & $\begin{array}{c}1.5 \\
6 \\
\end{array}$ & $\begin{array}{c}12.0 \\
9 \\
\end{array}$ & $\begin{array}{c}6.0 \\
4 \\
\end{array}$ & $\begin{array}{c}3.1 \\
2 \\
\end{array}$ & $\begin{array}{c}5.6 \\
5 \\
\end{array}$ & $\begin{array}{c}1.5 \\
6 \\
\end{array}$ & $\begin{array}{c}1.5 \\
6 \\
\end{array}$ & $\begin{array}{c}6.2 \\
4 \\
\end{array}$ & $\begin{array}{c}7.6 \\
0 \\
\end{array}$ & $\begin{array}{c}6.8 \\
2 \\
\end{array}$ & $\begin{array}{c}3.3 \\
1 \\
\end{array}$ & $\begin{array}{c}3.3 \\
1 \\
\end{array}$ & 513 \\
\hline Ranodon sibiricus & $\begin{array}{c}7.8 \\
0 \\
\end{array}$ & $\begin{array}{c}0.1 \\
9 \\
\end{array}$ & $\begin{array}{c}2.9 \\
2 \\
\end{array}$ & $\begin{array}{c}1.9 \\
5 \\
\end{array}$ & $\begin{array}{c}7.8 \\
0 \\
\end{array}$ & $\begin{array}{c}8.9 \\
7 \\
\end{array}$ & $\begin{array}{c}3.7 \\
0 \\
\end{array}$ & $\begin{array}{c}7.9 \\
9 \\
\end{array}$ & $\begin{array}{c}1.5 \\
6 \\
\end{array}$ & $\begin{array}{c}11.8 \\
9 \\
\end{array}$ & $\begin{array}{c}5.8 \\
5 \\
\end{array}$ & $\begin{array}{c}2.9 \\
2 \\
\end{array}$ & $\begin{array}{c}5.2 \\
6 \\
\end{array}$ & $\begin{array}{c}1.3 \\
6 \\
\end{array}$ & $\begin{array}{c}1.5 \\
6 \\
\end{array}$ & $\begin{array}{c}7.4 \\
1 \\
\end{array}$ & $\begin{array}{c}7.0 \\
2 \\
\end{array}$ & $\begin{array}{c}7.0 \\
2 \\
\end{array}$ & $\begin{array}{c}3.3 \\
1 \\
\end{array}$ & $\begin{array}{c}3.5 \\
1 \\
\end{array}$ & 513 \\
\hline Batrachuperus pinchonii & $\begin{array}{c}7.8 \\
0\end{array}$ & $\begin{array}{c}0.1 \\
9\end{array}$ & $\begin{array}{c}2.9 \\
2\end{array}$ & $\begin{array}{c}1.9 \\
5\end{array}$ & $\begin{array}{c}7.6 \\
0\end{array}$ & $\begin{array}{c}8.9 \\
7\end{array}$ & $\begin{array}{c}3.7 \\
0\end{array}$ & $\begin{array}{c}7.8 \\
0\end{array}$ & $\begin{array}{c}1.5 \\
6\end{array}$ & $\begin{array}{c}11.8 \\
9\end{array}$ & $\begin{array}{c}6.0 \\
4\end{array}$ & $\begin{array}{c}2.9 \\
2\end{array}$ & $\begin{array}{c}5.2 \\
6\end{array}$ & $\begin{array}{c}1.3 \\
6\end{array}$ & $\begin{array}{c}1.5 \\
6\end{array}$ & $\begin{array}{c}7.4 \\
1\end{array}$ & $\begin{array}{c}6.8 \\
2\end{array}$ & $\begin{array}{c}7.2 \\
1\end{array}$ & $\begin{array}{c}3.3 \\
1\end{array}$ & $\begin{array}{c}3.7 \\
0\end{array}$ & 513 \\
\hline
\end{tabular}


Hameed et al.

\begin{tabular}{|c|c|c|c|c|c|c|c|c|c|c|c|c|c|c|c|c|c|c|c|c|c|}
\hline $\begin{array}{l}\text { Onychodactylus } \\
\text { zhangyapingi }\end{array}$ & $\begin{array}{c}7.4 \\
2\end{array}$ & $\begin{array}{c}0.2 \\
0\end{array}$ & $\begin{array}{c}2.9 \\
3\end{array}$ & $\begin{array}{c}1.9 \\
5\end{array}$ & $\begin{array}{c}7.6 \\
2\end{array}$ & $\begin{array}{c}8.9 \\
8\end{array}$ & $\begin{array}{c}3.7 \\
1\end{array}$ & $\begin{array}{c}7.8 \\
1\end{array}$ & $\begin{array}{c}1.5 \\
6\end{array}$ & $\begin{array}{c}12.1 \\
1\end{array}$ & $\begin{array}{c}6.0 \\
5\end{array}$ & $\begin{array}{c}3.1 \\
3\end{array}$ & $\begin{array}{c}5.0 \\
8\end{array}$ & $\begin{array}{c}1.3 \\
7\end{array}$ & $\begin{array}{c}1.5 \\
6\end{array}$ & $\begin{array}{c}7.4 \\
2\end{array}$ & $\begin{array}{c}6.6 \\
4\end{array}$ & $\begin{array}{c}7.2 \\
3\end{array}$ & $\begin{array}{c}3.3 \\
2\end{array}$ & $\begin{array}{c}3.9 \\
1\end{array}$ & 512 \\
\hline Liua tsinpaensis & $\begin{array}{c}7.4 \\
1\end{array}$ & $\begin{array}{c}0.1 \\
9\end{array}$ & $\begin{array}{c}2.9 \\
2\end{array}$ & $\begin{array}{c}1.9 \\
5\end{array}$ & $\begin{array}{c}7.9 \\
9\end{array}$ & $\begin{array}{c}8.7 \\
7\end{array}$ & $\begin{array}{c}3.9 \\
0\end{array}$ & $\begin{array}{c}7.4 \\
1\end{array}$ & $\begin{array}{c}1.5 \\
6\end{array}$ & $\begin{array}{c}11.7 \\
0\end{array}$ & $\begin{array}{c}6.2 \\
4\end{array}$ & $\begin{array}{c}3.3 \\
1\end{array}$ & $\begin{array}{c}5.2 \\
6\end{array}$ & $\begin{array}{c}1.3 \\
6\end{array}$ & $\begin{array}{c}1.5 \\
6\end{array}$ & $\begin{array}{c}7.4 \\
1\end{array}$ & $\begin{array}{c}6.8 \\
2\end{array}$ & $\begin{array}{c}7.4 \\
1\end{array}$ & $\begin{array}{c}3.3 \\
1\end{array}$ & $\begin{array}{c}3.5 \\
1\end{array}$ & 513 \\
\hline $\begin{array}{c}\text { Alytes obstetricans } \\
\text { pertinax }\end{array}$ & $\begin{array}{c}8.5 \\
8\end{array}$ & $\begin{array}{c}0.1 \\
9\end{array}$ & $\begin{array}{c}2.9 \\
2\end{array}$ & $\begin{array}{c}2.1 \\
4\end{array}$ & $\begin{array}{c}7.9 \\
9\end{array}$ & $\begin{array}{c}9.1 \\
6\end{array}$ & $\begin{array}{c}3.7 \\
0\end{array}$ & $\begin{array}{c}7.2 \\
1\end{array}$ & $\begin{array}{c}1.5 \\
6\end{array}$ & $\begin{array}{c}11.7 \\
0\end{array}$ & $\begin{array}{c}5.8 \\
5\end{array}$ & $\begin{array}{c}2.9 \\
2\end{array}$ & $\begin{array}{c}5.2 \\
6\end{array}$ & $\begin{array}{c}1.3 \\
6\end{array}$ & $\begin{array}{c}1.7 \\
5\end{array}$ & $\begin{array}{c}5.4 \\
6\end{array}$ & $\begin{array}{c}7.8 \\
0\end{array}$ & $\begin{array}{c}7.8 \\
0\end{array}$ & $\begin{array}{c}3.1 \\
2\end{array}$ & $\begin{array}{c}3.5 \\
1\end{array}$ & 513 \\
\hline Bombina maxima & $\begin{array}{c}8.1 \\
9\end{array}$ & $\begin{array}{c}0.1 \\
9\end{array}$ & $\begin{array}{c}2.9 \\
2\end{array}$ & $\begin{array}{c}2.1 \\
4\end{array}$ & $\begin{array}{c}7.6 \\
0\end{array}$ & $\begin{array}{c}9.1 \\
6\end{array}$ & $\begin{array}{c}3.7 \\
0\end{array}$ & $\begin{array}{c}7.2 \\
1\end{array}$ & $\begin{array}{c}1.5 \\
6\end{array}$ & $\begin{array}{c}12.0 \\
9\end{array}$ & $\begin{array}{c}5.6 \\
5\end{array}$ & $\begin{array}{c}2.9 \\
2\end{array}$ & $\begin{array}{c}5.2 \\
6\end{array}$ & $\begin{array}{c}1.3 \\
6\end{array}$ & $\begin{array}{c}1.5 \\
6\end{array}$ & $\begin{array}{c}5.6 \\
5\end{array}$ & $\begin{array}{c}8.1 \\
9\end{array}$ & $\begin{array}{c}7.6 \\
0\end{array}$ & $\begin{array}{c}3.3 \\
1\end{array}$ & $\begin{array}{c}3.7 \\
0\end{array}$ & 513 \\
\hline Zearaja nasuta & $\begin{array}{c}8.3 \\
8\end{array}$ & $\begin{array}{c}0.1 \\
9\end{array}$ & $\begin{array}{c}2.7 \\
3\end{array}$ & $\begin{array}{c}2.1 \\
4\end{array}$ & $\begin{array}{c}7.6 \\
0\end{array}$ & $\begin{array}{c}8.9 \\
7\end{array}$ & $\begin{array}{c}3.5 \\
1\end{array}$ & $\begin{array}{c}8.1 \\
9\end{array}$ & $\begin{array}{c}1.5 \\
6\end{array}$ & $\begin{array}{c}12.2 \\
8 \\
\end{array}$ & $\begin{array}{c}5.0 \\
7\end{array}$ & $\begin{array}{c}3.1 \\
2\end{array}$ & $\begin{array}{c}5.4 \\
6\end{array}$ & $\begin{array}{c}1.5 \\
6\end{array}$ & $\begin{array}{c}1.5 \\
6\end{array}$ & $\begin{array}{c}6.2 \\
4\end{array}$ & $\begin{array}{c}6.6 \\
3\end{array}$ & $\begin{array}{c}7.8 \\
0\end{array}$ & $\begin{array}{c}3.3 \\
1\end{array}$ & $\begin{array}{c}3.7 \\
0\end{array}$ & 513 \\
\hline Dipturus trachyderma & $\begin{array}{c}8.3 \\
8\end{array}$ & $\begin{array}{c}0.1 \\
9\end{array}$ & $\begin{array}{c}2.7 \\
3\end{array}$ & $\begin{array}{c}2.1 \\
4\end{array}$ & $\begin{array}{c}7.6 \\
0\end{array}$ & $\begin{array}{c}8.9 \\
7\end{array}$ & $\begin{array}{c}3.5 \\
1\end{array}$ & $\begin{array}{c}7.9 \\
9\end{array}$ & $\begin{array}{c}1.5 \\
6\end{array}$ & $\begin{array}{c}12.2 \\
8\end{array}$ & $\begin{array}{c}5.0 \\
7\end{array}$ & $\begin{array}{c}3.1 \\
2\end{array}$ & $\begin{array}{c}5.4 \\
6\end{array}$ & $\begin{array}{c}1.5 \\
6\end{array}$ & $\begin{array}{c}1.5 \\
6\end{array}$ & $\begin{array}{c}6.2 \\
4\end{array}$ & $\begin{array}{c}6.6 \\
3\end{array}$ & $\begin{array}{c}7.9 \\
9\end{array}$ & $\begin{array}{c}3.3 \\
1\end{array}$ & $\begin{array}{c}3.7 \\
0\end{array}$ & 513 \\
\hline Zearaja chilensis & $\begin{array}{c}8.5 \\
8 \\
\end{array}$ & $\begin{array}{c}0.1 \\
9 \\
\end{array}$ & $\begin{array}{c}2.7 \\
3 \\
\end{array}$ & $\begin{array}{c}2.1 \\
4 \\
\end{array}$ & $\begin{array}{c}7.4 \\
1 \\
\end{array}$ & $\begin{array}{c}8.9 \\
7 \\
\end{array}$ & $\begin{array}{c}3.5 \\
1 \\
\end{array}$ & $\begin{array}{c}8.1 \\
9 \\
\end{array}$ & $\begin{array}{c}1.5 \\
6 \\
\end{array}$ & $\begin{array}{c}12.4 \\
8 \\
\end{array}$ & $\begin{array}{c}5.0 \\
7 \\
\end{array}$ & $\begin{array}{c}3.1 \\
2 \\
\end{array}$ & $\begin{array}{c}5.4 \\
6 \\
\end{array}$ & $\begin{array}{c}1.5 \\
6 \\
\end{array}$ & $\begin{array}{c}1.5 \\
6 \\
\end{array}$ & $\begin{array}{c}6.0 \\
4 \\
\end{array}$ & $\begin{array}{c}6.6 \\
3 \\
\end{array}$ & $\begin{array}{c}7.8 \\
0 \\
\end{array}$ & $\begin{array}{c}3.3 \\
1 \\
\end{array}$ & $\begin{array}{c}3.7 \\
0 \\
\end{array}$ & 513 \\
\hline Raja rhina & $\begin{array}{c}8.3 \\
8 \\
\end{array}$ & $\begin{array}{c}0.1 \\
9 \\
\end{array}$ & $\begin{array}{c}2.7 \\
3 \\
\end{array}$ & $\begin{array}{c}2.1 \\
4 \\
\end{array}$ & $\begin{array}{c}7.8 \\
0 \\
\end{array}$ & $\begin{array}{c}8.9 \\
7 \\
\end{array}$ & $\begin{array}{c}3.5 \\
1 \\
\end{array}$ & $\begin{array}{c}8.3 \\
8 \\
\end{array}$ & $\begin{array}{c}1.5 \\
6 \\
\end{array}$ & $\begin{array}{c}12.2 \\
8 \\
\end{array}$ & $\begin{array}{c}5.0 \\
7 \\
\end{array}$ & $\begin{array}{c}3.1 \\
2 \\
\end{array}$ & $\begin{array}{c}5.4 \\
6 \\
\end{array}$ & $\begin{array}{c}1.5 \\
6 \\
\end{array}$ & $\begin{array}{c}1.5 \\
6 \\
\end{array}$ & $\begin{array}{c}6.2 \\
4 \\
\end{array}$ & $\begin{array}{c}6.6 \\
3 \\
\end{array}$ & $\begin{array}{c}7.6 \\
0 \\
\end{array}$ & $\begin{array}{c}3.3 \\
1 \\
\end{array}$ & $\begin{array}{c}3.5 \\
1 \\
\end{array}$ & 513 \\
\hline Leucoraja erinacea & $\begin{array}{c}8.3 \\
8 \\
\end{array}$ & $\begin{array}{c}0.1 \\
9 \\
\end{array}$ & $\begin{array}{c}2.7 \\
3 \\
\end{array}$ & $\begin{array}{c}2.1 \\
4 \\
\end{array}$ & $\begin{array}{c}7.6 \\
0 \\
\end{array}$ & $\begin{array}{c}8.9 \\
7 \\
\end{array}$ & $\begin{array}{c}3.5 \\
1 \\
\end{array}$ & $\begin{array}{c}8.3 \\
8 \\
\end{array}$ & $\begin{array}{c}1.5 \\
6 \\
\end{array}$ & $\begin{array}{c}12.4 \\
8 \\
\end{array}$ & $\begin{array}{c}4.8 \\
7 \\
\end{array}$ & $\begin{array}{c}3.1 \\
2 \\
\end{array}$ & $\begin{array}{c}5.4 \\
6 \\
\end{array}$ & $\begin{array}{c}1.5 \\
6 \\
\end{array}$ & $\begin{array}{c}1.5 \\
6 \\
\end{array}$ & $\begin{array}{c}6.4 \\
3 \\
\end{array}$ & $\begin{array}{c}6.4 \\
3 \\
\end{array}$ & $\begin{array}{c}7.6 \\
0 \\
\end{array}$ & $\begin{array}{c}3.3 \\
1 \\
\end{array}$ & $\begin{array}{c}3.7 \\
0 \\
\end{array}$ & 513 \\
\hline Amblyraja georgiana & $\begin{array}{c}8.3 \\
8 \\
\end{array}$ & $\begin{array}{c}0.1 \\
9 \\
\end{array}$ & $\begin{array}{c}2.7 \\
3 \\
\end{array}$ & $\begin{array}{c}2.1 \\
4 \\
\end{array}$ & $\begin{array}{c}7.6 \\
0 \\
\end{array}$ & $\begin{array}{c}8.9 \\
7 \\
\end{array}$ & $\begin{array}{c}3.5 \\
1 \\
\end{array}$ & $\begin{array}{c}8.1 \\
9 \\
\end{array}$ & $\begin{array}{c}1.5 \\
6 \\
\end{array}$ & $\begin{array}{c}12.4 \\
8 \\
\end{array}$ & $\begin{array}{c}4.8 \\
7 \\
\end{array}$ & $\begin{array}{c}3.1 \\
2 \\
\end{array}$ & $\begin{array}{c}5.4 \\
6 \\
\end{array}$ & $\begin{array}{c}1.5 \\
6 \\
\end{array}$ & $\begin{array}{c}1.5 \\
6 \\
\end{array}$ & $\begin{array}{c}6.6 \\
3 \\
\end{array}$ & $\begin{array}{c}6.2 \\
4 \\
\end{array}$ & $\begin{array}{c}7.8 \\
0 \\
\end{array}$ & $\begin{array}{c}3.3 \\
1 \\
\end{array}$ & $\begin{array}{c}3.7 \\
0 \\
\end{array}$ & 513 \\
\hline Rajella fyllae & $\begin{array}{c}8.1 \\
9 \\
\end{array}$ & $\begin{array}{c}0.1 \\
9\end{array}$ & $\begin{array}{c}2.7 \\
3 \\
\end{array}$ & $\begin{array}{c}2.1 \\
4\end{array}$ & $\begin{array}{c}7.6 \\
0\end{array}$ & $\begin{array}{c}8.9 \\
7\end{array}$ & $\begin{array}{c}3.5 \\
1\end{array}$ & $\begin{array}{c}7.8 \\
0\end{array}$ & $\begin{array}{c}1.5 \\
6\end{array}$ & $\begin{array}{c}12.6 \\
7\end{array}$ & $\begin{array}{c}4.8 \\
7\end{array}$ & $\begin{array}{c}3.1 \\
2\end{array}$ & $\begin{array}{c}5.4 \\
6\end{array}$ & $\begin{array}{c}1.5 \\
6\end{array}$ & $\begin{array}{c}1.5 \\
6\end{array}$ & $\begin{array}{c}6.6 \\
3 \\
\end{array}$ & $\begin{array}{c}6.4 \\
3\end{array}$ & $\begin{array}{c}7.9 \\
9\end{array}$ & $\begin{array}{c}3.3 \\
1\end{array}$ & $\begin{array}{c}3.7 \\
0\end{array}$ & 513 \\
\hline Alopias pelagicus & $\begin{array}{c}8.7 \\
7 \\
\end{array}$ & $\begin{array}{c}0.1 \\
9 \\
\end{array}$ & $\begin{array}{c}2.7 \\
3 \\
\end{array}$ & $\begin{array}{c}2.1 \\
4\end{array}$ & $\begin{array}{c}7.4 \\
1 \\
\end{array}$ & $\begin{array}{c}8.9 \\
7 \\
\end{array}$ & $\begin{array}{c}3.7 \\
0\end{array}$ & $\begin{array}{c}8.1 \\
9 \\
\end{array}$ & $\begin{array}{c}1.5 \\
6\end{array}$ & $\begin{array}{c}12.4 \\
8\end{array}$ & $\begin{array}{c}4.8 \\
7 \\
\end{array}$ & $\begin{array}{c}2.9 \\
2\end{array}$ & $\begin{array}{c}5.6 \\
5\end{array}$ & $\begin{array}{c}1.5 \\
6\end{array}$ & $\begin{array}{c}1.5 \\
6\end{array}$ & $\begin{array}{c}6.0 \\
4\end{array}$ & $\begin{array}{c}6.4 \\
3 \\
\end{array}$ & $\begin{array}{c}7.8 \\
0\end{array}$ & $\begin{array}{c}3.3 \\
1\end{array}$ & $\begin{array}{c}3.7 \\
0\end{array}$ & 513 \\
\hline Scoliodon macrorhynchos & $\begin{array}{c}8.3 \\
8\end{array}$ & $\begin{array}{c}0.1 \\
9\end{array}$ & $\begin{array}{c}2.9 \\
2\end{array}$ & $\begin{array}{c}1.9 \\
5\end{array}$ & $\begin{array}{c}7.6 \\
0\end{array}$ & $\begin{array}{c}8.7 \\
7\end{array}$ & $\begin{array}{c}3.5 \\
1\end{array}$ & $\begin{array}{c}8.7 \\
7\end{array}$ & $\begin{array}{c}1.5 \\
6\end{array}$ & $\begin{array}{c}12.2 \\
8\end{array}$ & $\begin{array}{c}4.8 \\
7\end{array}$ & $\begin{array}{c}2.9 \\
2\end{array}$ & $\begin{array}{c}5.8 \\
5\end{array}$ & $\begin{array}{c}1.7 \\
5\end{array}$ & $\begin{array}{c}1.5 \\
6\end{array}$ & $\begin{array}{c}6.0 \\
4\end{array}$ & $\begin{array}{c}6.4 \\
3\end{array}$ & $\begin{array}{c}7.6 \\
0\end{array}$ & $\begin{array}{c}3.3 \\
1\end{array}$ & $\begin{array}{c}3.7 \\
0\end{array}$ & 513 \\
\hline Hemipristis elongata & $\begin{array}{c}8.3 \\
8\end{array}$ & $\begin{array}{c}0.1 \\
9\end{array}$ & $\begin{array}{c}2.9 \\
2\end{array}$ & $\begin{array}{c}1.9 \\
5\end{array}$ & $\begin{array}{c}7.6 \\
0\end{array}$ & $\begin{array}{c}8.7 \\
7\end{array}$ & $\begin{array}{c}3.7 \\
0\end{array}$ & $\begin{array}{c}8.7 \\
7\end{array}$ & $\begin{array}{c}1.5 \\
6\end{array}$ & $\begin{array}{c}12.4 \\
8\end{array}$ & $\begin{array}{c}5.0 \\
7\end{array}$ & $\begin{array}{c}2.9 \\
2\end{array}$ & $\begin{array}{c}5.8 \\
5\end{array}$ & $\begin{array}{c}1.7 \\
5\end{array}$ & $\begin{array}{c}1.5 \\
6\end{array}$ & $\begin{array}{c}5.8 \\
5\end{array}$ & $\begin{array}{c}6.4 \\
3\end{array}$ & $\begin{array}{c}7.4 \\
1\end{array}$ & $\begin{array}{c}3.3 \\
1\end{array}$ & $\begin{array}{c}3.5 \\
1\end{array}$ & 513 \\
\hline Anguis fragilis & $\begin{array}{c}8.1 \\
9\end{array}$ & $\begin{array}{c}0.3 \\
9\end{array}$ & $\begin{array}{c}2.9 \\
2\end{array}$ & $\begin{array}{c}1.7 \\
5\end{array}$ & $\begin{array}{c}7.6 \\
0\end{array}$ & $\begin{array}{c}9.3 \\
6\end{array}$ & $\begin{array}{c}3.9 \\
0\end{array}$ & $\begin{array}{c}8.1 \\
9\end{array}$ & $\begin{array}{c}1.7 \\
5\end{array}$ & $\begin{array}{c}11.1 \\
1\end{array}$ & $\begin{array}{c}5.4 \\
6\end{array}$ & $\begin{array}{c}2.7 \\
3\end{array}$ & $\begin{array}{c}5.2 \\
6\end{array}$ & $\begin{array}{c}1.3 \\
6\end{array}$ & $\begin{array}{c}1.5 \\
6\end{array}$ & $\begin{array}{c}6.4 \\
3\end{array}$ & $\begin{array}{c}7.4 \\
1\end{array}$ & $\begin{array}{c}7.4 \\
1\end{array}$ & $\begin{array}{c}3.3 \\
1\end{array}$ & $\begin{array}{c}3.9 \\
0\end{array}$ & 513 \\
\hline Dopasia gracilis & $\begin{array}{c}8.5 \\
8\end{array}$ & $\begin{array}{c}0.3 \\
9\end{array}$ & $\begin{array}{c}3.1 \\
2\end{array}$ & $\begin{array}{c}1.7 \\
5\end{array}$ & $\begin{array}{c}7.6 \\
0\end{array}$ & $\begin{array}{c}9.3 \\
6\end{array}$ & $\begin{array}{c}4.0 \\
9\end{array}$ & $\begin{array}{c}8.1 \\
9\end{array}$ & $\begin{array}{c}1.7 \\
5\end{array}$ & $\begin{array}{c}11.1 \\
1\end{array}$ & $\begin{array}{c}5.6 \\
5\end{array}$ & $\begin{array}{c}2.5 \\
3\end{array}$ & $\begin{array}{c}5.2 \\
6\end{array}$ & $\begin{array}{c}1.3 \\
6\end{array}$ & $\begin{array}{c}1.5 \\
6\end{array}$ & $\begin{array}{c}6.2 \\
4\end{array}$ & $\begin{array}{c}7.2 \\
1\end{array}$ & $\begin{array}{c}7.2 \\
1\end{array}$ & $\begin{array}{c}3.3 \\
1\end{array}$ & $\begin{array}{c}3.7 \\
0\end{array}$ & 513 \\
\hline Podarcis siculus & $\begin{array}{c}7.6 \\
0 \\
\end{array}$ & $\begin{array}{c}0.3 \\
9 \\
\end{array}$ & $\begin{array}{c}2.9 \\
2 \\
\end{array}$ & $\begin{array}{c}1.9 \\
5 \\
\end{array}$ & $\begin{array}{c}7.2 \\
1 \\
\end{array}$ & $\begin{array}{c}9.3 \\
6 \\
\end{array}$ & $\begin{array}{c}3.5 \\
1 \\
\end{array}$ & $\begin{array}{c}7.4 \\
1 \\
\end{array}$ & $\begin{array}{c}1.5 \\
6 \\
\end{array}$ & $\begin{array}{c}12.6 \\
7 \\
\end{array}$ & $\begin{array}{c}6.0 \\
4 \\
\end{array}$ & $\begin{array}{c}3.1 \\
2 \\
\end{array}$ & $\begin{array}{c}5.0 \\
7 \\
\end{array}$ & $\begin{array}{c}1.5 \\
6 \\
\end{array}$ & $\begin{array}{c}1.5 \\
6 \\
\end{array}$ & $\begin{array}{c}6.2 \\
4 \\
\end{array}$ & $\begin{array}{c}7.8 \\
0 \\
\end{array}$ & $\begin{array}{c}6.8 \\
2 \\
\end{array}$ & $\begin{array}{c}3.3 \\
1 \\
\end{array}$ & $\begin{array}{c}3.9 \\
0 \\
\end{array}$ & 513 \\
\hline Darevskia unisexualis & $\begin{array}{c}7.8 \\
1 \\
\end{array}$ & $\begin{array}{c}0.3 \\
9 \\
\end{array}$ & $\begin{array}{c}3.1 \\
3 \\
\end{array}$ & $\begin{array}{c}1.9 \\
5 \\
\end{array}$ & $\begin{array}{c}7.2 \\
3 \\
\end{array}$ & $\begin{array}{c}9.1 \\
8 \\
\end{array}$ & $\begin{array}{c}3.5 \\
2 \\
\end{array}$ & $\begin{array}{c}7.2 \\
3 \\
\end{array}$ & $\begin{array}{c}1.5 \\
6 \\
\end{array}$ & $\begin{array}{c}13.0 \\
9 \\
\end{array}$ & $\begin{array}{c}5.2 \\
7 \\
\end{array}$ & $\begin{array}{c}2.9 \\
3 \\
\end{array}$ & $\begin{array}{c}5.2 \\
7 \\
\end{array}$ & $\begin{array}{c}1.5 \\
6 \\
\end{array}$ & $\begin{array}{c}1.5 \\
6 \\
\end{array}$ & $\begin{array}{c}5.8 \\
6 \\
\end{array}$ & $\begin{array}{c}8.0 \\
1 \\
\end{array}$ & $\begin{array}{c}7.2 \\
3 \\
\end{array}$ & $\begin{array}{c}3.3 \\
2 \\
\end{array}$ & $\begin{array}{c}3.9 \\
1 \\
\end{array}$ & 512 \\
\hline Scincella vandenburghi & $\begin{array}{c}8.1 \\
9\end{array}$ & $\begin{array}{c}0.3 \\
9\end{array}$ & $\begin{array}{c}2.9 \\
2\end{array}$ & $\begin{array}{c}1.9 \\
5\end{array}$ & $\begin{array}{c}7.6 \\
0\end{array}$ & $\begin{array}{c}9.3 \\
6\end{array}$ & $\begin{array}{c}3.7 \\
0\end{array}$ & $\begin{array}{c}7.2 \\
1\end{array}$ & $\begin{array}{c}1.5 \\
6\end{array}$ & $\begin{array}{c}11.8 \\
9\end{array}$ & $\begin{array}{c}5.8 \\
5\end{array}$ & $\begin{array}{c}2.9 \\
2\end{array}$ & $\begin{array}{c}5.2 \\
6\end{array}$ & $\begin{array}{c}1.5 \\
6\end{array}$ & $\begin{array}{c}1.5 \\
6\end{array}$ & $\begin{array}{c}5.8 \\
5\end{array}$ & $\begin{array}{c}7.4 \\
1\end{array}$ & $\begin{array}{c}7.6 \\
0\end{array}$ & $\begin{array}{c}3.3 \\
1\end{array}$ & $\begin{array}{c}3.9 \\
0\end{array}$ & 513 \\
\hline
\end{tabular}


Pure Appl. Biol., 9(3): 1995-2006, September, 2020 http://dx.doi.org/10.19045/bspab.2020.90213

\begin{tabular}{|c|c|c|c|c|c|c|c|c|c|c|c|c|c|c|c|c|c|c|c|c|c|}
\hline Sphenomorphus incognitus & $\begin{array}{c}7.9 \\
9\end{array}$ & $\begin{array}{c}0.3 \\
9\end{array}$ & $\begin{array}{c}2.9 \\
2\end{array}$ & $\begin{array}{c}1.9 \\
5\end{array}$ & $\begin{array}{c}7.8 \\
0\end{array}$ & $\begin{array}{c}9.3 \\
6\end{array}$ & $\begin{array}{c}3.7 \\
0\end{array}$ & $\begin{array}{c}7.4 \\
1\end{array}$ & $\begin{array}{c}1.5 \\
6\end{array}$ & $\begin{array}{c}11.5 \\
0\end{array}$ & $\begin{array}{c}5.8 \\
5\end{array}$ & $\begin{array}{c}2.9 \\
2\end{array}$ & $\begin{array}{c}5.2 \\
6\end{array}$ & $\begin{array}{c}1.5 \\
6\end{array}$ & $\begin{array}{c}1.5 \\
6\end{array}$ & $\begin{array}{c}5.6 \\
5\end{array}$ & $\begin{array}{c}7.8 \\
0\end{array}$ & $\begin{array}{c}7.6 \\
0\end{array}$ & $\begin{array}{c}3.3 \\
1\end{array}$ & $\begin{array}{c}3.9 \\
0\end{array}$ & 513 \\
\hline Leiocephalus personatus & $\begin{array}{c}8.3 \\
8\end{array}$ & $\begin{array}{c}0.3 \\
9\end{array}$ & $\begin{array}{c}2.9 \\
2\end{array}$ & $\begin{array}{c}1.9 \\
5\end{array}$ & $\begin{array}{c}7.9 \\
9\end{array}$ & $\begin{array}{c}9.3 \\
6\end{array}$ & $\begin{array}{c}3.5 \\
1\end{array}$ & $\begin{array}{c}7.8 \\
0\end{array}$ & $\begin{array}{c}1.7 \\
5\end{array}$ & $\begin{array}{c}11.7 \\
0\end{array}$ & $\begin{array}{c}6.0 \\
4\end{array}$ & $\begin{array}{c}2.9 \\
2\end{array}$ & $\begin{array}{c}5.2 \\
6\end{array}$ & $\begin{array}{c}1.5 \\
6\end{array}$ & $\begin{array}{c}1.5 \\
6\end{array}$ & $\begin{array}{c}5.6 \\
5\end{array}$ & $\begin{array}{c}7.2 \\
1\end{array}$ & $\begin{array}{c}7.0 \\
2\end{array}$ & $\begin{array}{c}3.3 \\
1\end{array}$ & $\begin{array}{c}3.7 \\
0\end{array}$ & 513 \\
\hline Basiliscus vittatus & $\begin{array}{c}8.3 \\
8 \\
\end{array}$ & $\begin{array}{c}0.3 \\
9\end{array}$ & $\begin{array}{c}2.9 \\
2\end{array}$ & $\begin{array}{c}1.9 \\
5\end{array}$ & $\begin{array}{c}7.8 \\
0\end{array}$ & $\begin{array}{c}9.3 \\
6\end{array}$ & $\begin{array}{c}3.5 \\
1\end{array}$ & $\begin{array}{c}7.9 \\
9\end{array}$ & $\begin{array}{c}1.5 \\
6\end{array}$ & $\begin{array}{c}11.8 \\
9\end{array}$ & $\begin{array}{c}5.8 \\
5\end{array}$ & $\begin{array}{c}2.9 \\
2\end{array}$ & $\begin{array}{c}5.2 \\
6\end{array}$ & $\begin{array}{c}1.7 \\
5\end{array}$ & $\begin{array}{c}1.5 \\
6\end{array}$ & $\begin{array}{c}5.8 \\
5\end{array}$ & $\begin{array}{c}7.2 \\
1\end{array}$ & $\begin{array}{c}6.6 \\
3\end{array}$ & $\begin{array}{c}3.3 \\
1\end{array}$ & $\begin{array}{c}3.9 \\
0\end{array}$ & 513 \\
\hline Petrosaurus thalassinus & $\begin{array}{c}8.3 \\
8 \\
\end{array}$ & $\begin{array}{c}0.3 \\
9\end{array}$ & $\begin{array}{c}2.9 \\
2 \\
\end{array}$ & $\begin{array}{c}1.9 \\
5\end{array}$ & $\begin{array}{c}7.8 \\
0 \\
\end{array}$ & $\begin{array}{c}9.1 \\
6\end{array}$ & $\begin{array}{c}3.7 \\
0\end{array}$ & $\begin{array}{c}7.0 \\
2 \\
\end{array}$ & $\begin{array}{c}1.5 \\
6\end{array}$ & $\begin{array}{c}11.7 \\
0\end{array}$ & $\begin{array}{c}6.0 \\
4 \\
\end{array}$ & $\begin{array}{c}2.9 \\
2 \\
\end{array}$ & $\begin{array}{c}5.2 \\
6\end{array}$ & $\begin{array}{c}1.5 \\
6\end{array}$ & $\begin{array}{c}1.5 \\
6\end{array}$ & $\begin{array}{c}6.0 \\
4 \\
\end{array}$ & $\begin{array}{c}7.2 \\
1 \\
\end{array}$ & $\begin{array}{c}7.6 \\
0\end{array}$ & $\begin{array}{c}3.3 \\
1\end{array}$ & $\begin{array}{c}3.9 \\
0\end{array}$ & 513 \\
\hline Holbrookia lacerata & $\begin{array}{c}8.7 \\
5\end{array}$ & $\begin{array}{c}0.2 \\
1\end{array}$ & $\begin{array}{c}2.9 \\
2 \\
\end{array}$ & $\begin{array}{c}1.2 \\
5\end{array}$ & $\begin{array}{c}8.3 \\
3\end{array}$ & $\begin{array}{c}9.5 \\
8\end{array}$ & $\begin{array}{c}3.3 \\
3\end{array}$ & $\begin{array}{c}7.2 \\
9\end{array}$ & $\begin{array}{c}1.6 \\
7\end{array}$ & $\begin{array}{c}11.4 \\
6 \\
\end{array}$ & $\begin{array}{c}6.6 \\
7\end{array}$ & $\begin{array}{c}2.9 \\
2\end{array}$ & $\begin{array}{c}4.7 \\
9\end{array}$ & $\begin{array}{c}1.6 \\
7\end{array}$ & $\begin{array}{c}1.6 \\
7\end{array}$ & $\begin{array}{c}6.0 \\
4\end{array}$ & $\begin{array}{c}6.6 \\
7\end{array}$ & $\begin{array}{c}7.9 \\
2\end{array}$ & $\begin{array}{c}3.3 \\
3\end{array}$ & $\begin{array}{c}3.5 \\
4\end{array}$ & 480 \\
\hline Danic & $\begin{array}{c}9.1 \\
6\end{array}$ & $\begin{array}{c}0.1 \\
9\end{array}$ & $\begin{array}{c}2.7 \\
3\end{array}$ & $\begin{array}{c}2.1 \\
4\end{array}$ & $\begin{array}{c}8.1 \\
9\end{array}$ & $\begin{array}{c}9.1 \\
6\end{array}$ & $\begin{array}{c}3.5 \\
1\end{array}$ & $\begin{array}{c}7.4 \\
1\end{array}$ & $\begin{array}{c}1.5 \\
6\end{array}$ & $\begin{array}{c}12.2 \\
8\end{array}$ & $\begin{array}{c}4.6 \\
8\end{array}$ & $\begin{array}{c}2.9 \\
2\end{array}$ & $\begin{array}{c}5.4 \\
6\end{array}$ & $\begin{array}{c}1.3 \\
6\end{array}$ & $\begin{array}{c}1.5 \\
6\end{array}$ & $\begin{array}{c}5.0 \\
7\end{array}$ & $\begin{array}{c}7.4 \\
1\end{array}$ & $\begin{array}{c}8.3 \\
8\end{array}$ & $\begin{array}{c}3.3 \\
1\end{array}$ & $\begin{array}{c}3.5 \\
1\end{array}$ & 513 \\
\hline Carassius auratus & $\begin{array}{c}9.1 \\
6 \\
\end{array}$ & $\begin{array}{c}0.1 \\
9 \\
\end{array}$ & $\begin{array}{c}2.7 \\
3 \\
\end{array}$ & $\begin{array}{c}2.1 \\
4 \\
\end{array}$ & $\begin{array}{c}7.8 \\
0 \\
\end{array}$ & $\begin{array}{c}8.9 \\
7 \\
\end{array}$ & $\begin{array}{c}3.7 \\
0 \\
\end{array}$ & $\begin{array}{c}7.4 \\
1 \\
\end{array}$ & $\begin{array}{c}1.5 \\
6 \\
\end{array}$ & $\begin{array}{c}12.4 \\
8 \\
\end{array}$ & $\begin{array}{c}4.8 \\
7 \\
\end{array}$ & $\begin{array}{c}2.7 \\
3 \\
\end{array}$ & $\begin{array}{c}5.4 \\
6 \\
\end{array}$ & $\begin{array}{c}1.3 \\
6 \\
\end{array}$ & $\begin{array}{c}1.5 \\
6 \\
\end{array}$ & $\begin{array}{c}5.8 \\
5 \\
\end{array}$ & $\begin{array}{c}6.8 \\
2 \\
\end{array}$ & $\begin{array}{c}8.1 \\
9 \\
\end{array}$ & $\begin{array}{c}3.3 \\
1 \\
\end{array}$ & $\begin{array}{c}3.7 \\
0 \\
\end{array}$ & 513 \\
\hline Heniochus diphreutes & $\begin{array}{c}8.9 \\
7 \\
\end{array}$ & $\begin{array}{c}0.1 \\
9 \\
\end{array}$ & $\begin{array}{c}2.9 \\
2 \\
\end{array}$ & $\begin{array}{c}2.1 \\
4 \\
\end{array}$ & $\begin{array}{c}8.1 \\
9 \\
\end{array}$ & $\begin{array}{c}9.1 \\
6 \\
\end{array}$ & $\begin{array}{c}3.7 \\
0 \\
\end{array}$ & $\begin{array}{c}7.6 \\
0 \\
\end{array}$ & $\begin{array}{c}1.5 \\
6 \\
\end{array}$ & $\begin{array}{c}12.4 \\
8 \\
\end{array}$ & $\begin{array}{c}4.8 \\
7 \\
\end{array}$ & $\begin{array}{c}2.7 \\
3 \\
\end{array}$ & $\begin{array}{c}5.4 \\
6 \\
\end{array}$ & $\begin{array}{c}1.3 \\
6 \\
\end{array}$ & $\begin{array}{c}1.5 \\
6 \\
\end{array}$ & $\begin{array}{c}5.4 \\
6 \\
\end{array}$ & $\begin{array}{c}7.2 \\
1 \\
\end{array}$ & $\begin{array}{c}7.6 \\
0 \\
\end{array}$ & $\begin{array}{c}3.3 \\
1 \\
\end{array}$ & $\begin{array}{c}3.5 \\
1 \\
\end{array}$ & 513 \\
\hline Sillago aeolus & $\begin{array}{c}8.9 \\
7 \\
\end{array}$ & $\begin{array}{c}0.1 \\
9 \\
\end{array}$ & $\begin{array}{c}2.7 \\
3 \\
\end{array}$ & $\begin{array}{c}2.3 \\
4 \\
\end{array}$ & $\begin{array}{c}7.8 \\
0 \\
\end{array}$ & $\begin{array}{c}8.7 \\
7 \\
\end{array}$ & $\begin{array}{c}3.7 \\
0 \\
\end{array}$ & $\begin{array}{c}7.4 \\
1 \\
\end{array}$ & $\begin{array}{c}1.5 \\
6 \\
\end{array}$ & $\begin{array}{c}12.4 \\
8 \\
\end{array}$ & $\begin{array}{c}4.6 \\
8 \\
\end{array}$ & $\begin{array}{c}2.7 \\
3 \\
\end{array}$ & $\begin{array}{c}5.4 \\
6 \\
\end{array}$ & $\begin{array}{c}1.3 \\
6 \\
\end{array}$ & $\begin{array}{c}1.5 \\
6 \\
\end{array}$ & $\begin{array}{c}5.8 \\
5\end{array}$ & $\begin{array}{c}7.2 \\
1 \\
\end{array}$ & $\begin{array}{c}8.1 \\
9 \\
\end{array}$ & $\begin{array}{c}3.3 \\
1 \\
\end{array}$ & $\begin{array}{c}3.7 \\
0 \\
\end{array}$ & 513 \\
\hline Amphiprion ocellaris & $\begin{array}{c}8.7 \\
7 \\
\end{array}$ & $\begin{array}{c}0.1 \\
9 \\
\end{array}$ & $\begin{array}{c}2.9 \\
2 \\
\end{array}$ & $\begin{array}{c}1.9 \\
5 \\
\end{array}$ & $\begin{array}{c}8.1 \\
9 \\
\end{array}$ & $\begin{array}{c}9.1 \\
6 \\
\end{array}$ & $\begin{array}{c}3.7 \\
0 \\
\end{array}$ & $\begin{array}{c}7.2 \\
1 \\
\end{array}$ & $\begin{array}{c}1.5 \\
6 \\
\end{array}$ & $\begin{array}{c}12.0 \\
9 \\
\end{array}$ & $\begin{array}{c}4.8 \\
7 \\
\end{array}$ & $\begin{array}{c}2.7 \\
3 \\
\end{array}$ & $\begin{array}{c}5.4 \\
6 \\
\end{array}$ & $\begin{array}{c}1.3 \\
6 \\
\end{array}$ & $\begin{array}{c}1.5 \\
6 \\
\end{array}$ & $\begin{array}{c}5.2 \\
6 \\
\end{array}$ & $\begin{array}{c}7.4 \\
1 \\
\end{array}$ & $\begin{array}{c}8.5 \\
8 \\
\end{array}$ & $\begin{array}{c}3.5 \\
1 \\
\end{array}$ & $\begin{array}{c}3.5 \\
1 \\
\end{array}$ & 513 \\
\hline Antigonia capros & $\begin{array}{c}9.3 \\
6\end{array}$ & $\begin{array}{c}0.1 \\
9 \\
\end{array}$ & $\begin{array}{c}2.9 \\
2 \\
\end{array}$ & $\begin{array}{c}1.9 \\
5\end{array}$ & $\begin{array}{c}8.1 \\
9 \\
\end{array}$ & $\begin{array}{c}8.9 \\
7\end{array}$ & $\begin{array}{c}3.7 \\
0\end{array}$ & $\begin{array}{c}7.9 \\
9 \\
\end{array}$ & $\begin{array}{c}1.5 \\
6\end{array}$ & $\begin{array}{c}12.2 \\
8 \\
\end{array}$ & $\begin{array}{c}4.6 \\
8\end{array}$ & $\begin{array}{c}2.9 \\
2\end{array}$ & $\begin{array}{c}5.4 \\
6\end{array}$ & $\begin{array}{c}1.5 \\
6\end{array}$ & $\begin{array}{c}1.5 \\
6\end{array}$ & $\begin{array}{c}5.0 \\
7\end{array}$ & $\begin{array}{c}7.0 \\
2\end{array}$ & $\begin{array}{c}7.8 \\
0\end{array}$ & $\begin{array}{c}3.3 \\
1\end{array}$ & $\begin{array}{c}3.5 \\
1\end{array}$ & 513 \\
\hline Oryzias latipes & $\begin{array}{c}8.5 \\
8 \\
\end{array}$ & $\begin{array}{c}0.1 \\
9\end{array}$ & $\begin{array}{c}2.7 \\
3 \\
\end{array}$ & $\begin{array}{c}2.1 \\
4 \\
\end{array}$ & $\begin{array}{c}8.1 \\
9 \\
\end{array}$ & $\begin{array}{c}9.1 \\
6\end{array}$ & $\begin{array}{c}3.7 \\
0\end{array}$ & $\begin{array}{c}8.3 \\
8 \\
\end{array}$ & $\begin{array}{c}1.5 \\
6\end{array}$ & $\begin{array}{c}12.2 \\
8\end{array}$ & $\begin{array}{c}5.0 \\
7\end{array}$ & $\begin{array}{c}2.7 \\
3 \\
\end{array}$ & $\begin{array}{c}5.4 \\
6\end{array}$ & $\begin{array}{c}1.3 \\
6\end{array}$ & $\begin{array}{c}1.5 \\
6\end{array}$ & $\begin{array}{c}6.2 \\
4 \\
\end{array}$ & $\begin{array}{c}6.8 \\
2 \\
\end{array}$ & $\begin{array}{c}7.0 \\
2 \\
\end{array}$ & $\begin{array}{c}3.3 \\
1\end{array}$ & $\begin{array}{c}3.5 \\
1\end{array}$ & 513 \\
\hline Mastacembelus armatus & $\begin{array}{c}9.1 \\
6\end{array}$ & $\begin{array}{c}0.1 \\
9\end{array}$ & $\begin{array}{c}2.9 \\
2\end{array}$ & $\begin{array}{c}2.1 \\
4\end{array}$ & $\begin{array}{c}8.1 \\
9\end{array}$ & $\begin{array}{c}8.5 \\
8\end{array}$ & $\begin{array}{c}3.7 \\
0\end{array}$ & $\begin{array}{c}8.1 \\
9\end{array}$ & $\begin{array}{c}1.5 \\
6\end{array}$ & $\begin{array}{c}12.2 \\
8\end{array}$ & $\begin{array}{c}4.8 \\
7\end{array}$ & $\begin{array}{c}2.7 \\
3\end{array}$ & $\begin{array}{c}5.6 \\
5\end{array}$ & $\begin{array}{c}1.3 \\
6\end{array}$ & $\begin{array}{c}1.5 \\
6\end{array}$ & $\begin{array}{c}5.8 \\
5\end{array}$ & $\begin{array}{c}7.2 \\
1\end{array}$ & $\begin{array}{c}7.0 \\
2\end{array}$ & $\begin{array}{c}3.3 \\
1\end{array}$ & $\begin{array}{c}3.5 \\
1\end{array}$ & 513 \\
\hline Epinephelus coioides & $\begin{array}{c}9.1 \\
6 \\
\end{array}$ & $\begin{array}{c}0.1 \\
9 \\
\end{array}$ & $\begin{array}{c}2.7 \\
3 \\
\end{array}$ & $\begin{array}{c}2.1 \\
4 \\
\end{array}$ & $\begin{array}{c}8.1 \\
9 \\
\end{array}$ & $\begin{array}{c}8.9 \\
7 \\
\end{array}$ & $\begin{array}{c}3.7 \\
0 \\
\end{array}$ & $\begin{array}{c}8.1 \\
9 \\
\end{array}$ & $\begin{array}{c}1.5 \\
6 \\
\end{array}$ & $\begin{array}{c}11.8 \\
9 \\
\end{array}$ & $\begin{array}{c}5.0 \\
7 \\
\end{array}$ & $\begin{array}{c}2.7 \\
3 \\
\end{array}$ & $\begin{array}{c}5.4 \\
6 \\
\end{array}$ & $\begin{array}{c}1.3 \\
6 \\
\end{array}$ & $\begin{array}{c}1.5 \\
6 \\
\end{array}$ & $\begin{array}{c}5.4 \\
6 \\
\end{array}$ & $\begin{array}{c}7.2 \\
1 \\
\end{array}$ & $\begin{array}{c}7.6 \\
0 \\
\end{array}$ & $\begin{array}{c}3.3 \\
1 \\
\end{array}$ & $\begin{array}{c}3.5 \\
1 \\
\end{array}$ & 513 \\
\hline Seriola dumerili & $\begin{array}{c}9.5 \\
5\end{array}$ & $\begin{array}{c}0.1 \\
9\end{array}$ & $\begin{array}{c}2.9 \\
2\end{array}$ & $\begin{array}{c}2.1 \\
4\end{array}$ & $\begin{array}{c}8.1 \\
9\end{array}$ & $\begin{array}{c}9.1 \\
6\end{array}$ & $\begin{array}{c}3.9 \\
0\end{array}$ & $\begin{array}{c}7.6 \\
0\end{array}$ & $\begin{array}{c}1.5 \\
6\end{array}$ & $\begin{array}{c}12.0 \\
9\end{array}$ & $\begin{array}{c}4.6 \\
8\end{array}$ & $\begin{array}{c}2.7 \\
3\end{array}$ & $\begin{array}{c}5.2 \\
6\end{array}$ & $\begin{array}{c}1.1 \\
7\end{array}$ & $\begin{array}{c}1.5 \\
6\end{array}$ & $\begin{array}{c}5.2 \\
6\end{array}$ & $\begin{array}{c}6.6 \\
3\end{array}$ & $\begin{array}{c}8.5 \\
8\end{array}$ & $\begin{array}{c}3.3 \\
1\end{array}$ & $\begin{array}{c}3.5 \\
1\end{array}$ & 513 \\
\hline Avg. & $\begin{array}{c}8.4 \\
0\end{array}$ & $\begin{array}{c}0.2 \\
2\end{array}$ & $\begin{array}{c}2.9 \\
0\end{array}$ & $\begin{array}{c}1.9 \\
5\end{array}$ & $\begin{array}{c}7.9 \\
3\end{array}$ & $\begin{array}{c}9.0 \\
8\end{array}$ & $\begin{array}{c}3.6 \\
3\end{array}$ & $\begin{array}{c}7.6 \\
9\end{array}$ & $\begin{array}{c}1.6 \\
4\end{array}$ & $\begin{array}{c}12.0 \\
7\end{array}$ & $\begin{array}{c}5.4 \\
3\end{array}$ & $\begin{array}{c}2.9 \\
7\end{array}$ & $\begin{array}{c}5.5 \\
0\end{array}$ & $\begin{array}{c}1.4 \\
5\end{array}$ & $\begin{array}{c}1.5 \\
6\end{array}$ & $\begin{array}{c}5.9 \\
9\end{array}$ & $\begin{array}{c}7.1 \\
8\end{array}$ & $\begin{array}{c}7.4 \\
1\end{array}$ & $\begin{array}{c}3.3 \\
0\end{array}$ & $\begin{array}{c}3.6 \\
8\end{array}$ & $\begin{array}{c}512 . \\
4\end{array}$ \\
\hline
\end{tabular}




\section{Discussion}

In current study, the reconstruction of a reference phylogenetic tree to find closely or distinctly related organisms was the main objective. For a good phylogenetic analysis, it is required to use an appropriate subject (gene/protein) and a good tree building method. A study has shown that amino acid sequences are generally more informative than nucleotide sequences for constructing reliable trees [13]. Therefore, choice of protein sequences is more appropriate over nucleotide sequences. Because of its presence in all the organisms cytochrome oxidase subunit 1 was chosen in this study as COXI residues are conserved at most positions involved in enzyme function [14]. It is a difficult and tricky problem to compare the relative efficiencies of different tree-building methods in obtaining correct topologies because the theoretical basis of each method is not well established. Mustafa [15] stated that in an evolutionary study which is an "after-trial" evaluation, the maximum-likelihood (ML) method is known to be the best. However, it should be noted that the topology estimation in phylogenetic analysis is not the same as the estimation of parameters in the classical theory of the ML method because the maximization of likelihood is conducted separately for different topologies (different probability spaces) [16]. Indeed, it is not difficult to construct examples in which the ML method is inferior to the maximum parsimony (MP) and neighbor-joining ( $\mathrm{NJ}$ ) methods [16]. Of course, a series of computer simulations have shown that ML is generally slightly better than other methods in many different situations [17] but still we do not know the general property of this method [18]. Therefore, ML method was selected in this study for generation of a phylogenetic tree. To check the reliability of the generated phylogram it should be compared with the known phylogeny. In mammalian clade, it has been observed that Pan troglodytes, Homo sapiens and Gorilla gorilla gorilla are falling together. The closed branch to this subclade involves Nomascus gabriellae and Hylobates lar (Gibbons). The similar results have been shown by [19]. This tree also presented that the monophyletic group of Mammalia is distantly related to other selected classes. The physiology of mammals and birds share a number of highly similar characteristics including but not limited to enhanced hearing, vocal communication, endothermy, insulation, shivering, respiratory turbinates, high basal metabolism, grinding, sustained activity, four chambered heart, high blood pressure and intensive parental care [20]. These bird-mammal shared characteristics (BMSC) are considered to have evolved convergently in the two groups [21]. Chondrichthyes and Osteichthyes being two classes of fishes are arising from same node while Amphibia and Reptillia are arising from another node and showing their strong evolutionary relationships.

Common node of Reptillia and Amphibia suggested a common ancestor. A previous study conducted using 12 genes included nine nuclear genes (i.e. $\mathrm{C}-\mathrm{X}-\mathrm{C}$ chemokine receptor type 4, histone $3 \mathrm{a}$, sodiumcalcium exchanger, pro-opiomelanocortin, recombination-activating gene 1 , rhodopsin, seventh-in-absentia, solutecarrier family, and tyrosinase), and three mitochondrial genes were also included (i.e. cytochrome $b$, and the large and small subunits of the mitochondrial ribosome genes) have shown the same results for Amphibians [22]. The results of Cynops pyrrhogaster and Triturus pygmaeus have also matched which shows the accuracy of COX1 and this tree in phylogenetic analysis. Salamandra atra and Echinotriton andersoni shared a common ancestor. Therefore, they are closely related to each other as compared to Ranodon sibiricus that was confusion at a time. Studies using morphology and fossils suggested that Salamandra atra is closely related to $R$. sibiricus [23] but protein barcoding suggested the vice versa. Therefore, the comparisons of genes from various 
organisms are very useful for their evolutionary studies [24].

Two families of class Reptillia (i.e. Leiocephalidae and Corytophanidae) share a common ancestor. Leiocephalus personatus (NCBI:txid 211984) belongs to family Leiocephalidae while Basiliscus vittatus ( NCBI:txid211979) belongs to Corytophanidae family. One of the defining features of these lizards is that their tail often curls over. Corytophanidae is a family of iguanian lizards, also called casquehead lizards or helmeted lizards. Both of these species are morphologically distant from each other but the protein analysis has showed that they have strong evolutionary relationships and shared a common ancestor. It shows the drawback of phylogeny on the basis of morphology only.

\section{Conclusion}

Protein barcoding is relatively a new but more accurate method to determine phylogenetic relationships among organisms. COX1 has shown very reliable results. Amphibians are closely related to Reptiles while Chondrichthyes is closely related to Osteichthyes. Two families of class Reptillia (i.e. Leiocephalidae and Corytophanidae) share a common ancestor that shows the drawbacks of phylogeny using fossil records and morphology. More studies should be conducted to precisely classify organisms. Therefore, it is recommended to use more reliable methods such as protein barcoding along with morphology for classification. We also recommend using COX1 for classification system.

\section{Authors' contributions}

Conceived and designed the experiments: $\mathrm{G}$ Mustafa, Performed the experiments: U Hameed, S Khalid \& S Javed, Analyzed the data: G Mustafa, Contributed materials/ analysis/ tools: S Khalid \& S Javed, Wrote the paper: U Hameed \& G Mustafa.

\section{Acknowledgements}

We are grateful to Higher Education Commission (HEC) Islamabad, Government of Pakistan.

\section{References}

1. Tsukihara T, Aoyama H, Yamashita E, Tomizaki T, Yamaguchi H, ShinzawaItoh K, Nakashima R, Yaono R \& Yoshikawa $S$ (1996). The whole structure of the 13-subunit oxidized cytochrome c oxidase at $2.8 \AA$. Science 272: 1136-1144.

2. Mustafa G, Asgher M, Mehboob-urRahman \& Jamil A (2014). Citrate synthase gene comparison and use of RAPD genomic fingerprinting to study relatedness among different Aspergillus sp (912.1). FASEB $J$ 28: Supplement 912.1.

3. Ejaz S, Choudhary MS, Mustafa G, Ashraf M \& Rehman J (2018). Isolation and characteristics of biotechnologically important antagonistic thermophilic bacteria from rhizosphere of Haloxylon salicornicum. Pol J Microbiol 67: 4958.

4. Jabbir F, Irfan M, Mustafa G \& Ahmad HI (2019). Bioinformatics Approaches to Explore the Phylogeny and Role of BRCA1 in Breast Cancer. Crit Rev Eukaryot Gene Expr 29: 551-564.

5. Bukhari SA, Tahir MF, Akhter N, Anjum F, Anwar H \& Mustafa G (2018). Phylogeny and comparative modeling of phytochelatin synthase from Chlorella sp. as an efficient bioagent for detoxification of heavy metals. J Biol Reg Homeos Ag 32: 1191-1197.

6. Yang $\mathrm{Z}$ (2005). The power of phylogenetic comparison in revealing protein function. Proc Natl Acad Sci USA 102: 3179-3180.

7. Sawyer SL, Wu LI, Emerman M \& Malik HS (2005). Positive selection of primate TRIM5a identifies a critical speciesspecific retroviral restriction domain. Proc Natl Acad Sci USA 102: 2832-2837.

8. Altschul SF, Gish W, Miller W, Myers EW \& Lipman DJ (1990). Basic local 
alignment search tool. J Mol Biol 215: 403-410.

9. Tamura K, Peterson D, Peterson N, Stecher G, Nei M \& Kumar S (2011). MEGA5: molecular evolutionary genetics analysis using maximum likelihood, evolutionary distance, and maximum parsimony methods. Mol Biol Evol 28: 2731-2739.

10. Mustafa G, Iqbal MJ, Hassan M \& Jamil A (2017). Bioinformatics characterization of growth differentiation factor 11 of Oryctolagus cuniculus. J Chem Soc Pak 39: 1089-1095.

11. Felsenstein J (1985). Confidence limits on phylogenies: An approach using the bootstrap. Evolution 39: 783-791.

12. Zuckerkandl E \& Pauling L (1965). Evolutionary divergence and convergence in proteins. Edited in Evolving Genes and Proteins by V Bryson and HJ Vogel, pp 97-166. Academic Press, New York.

13. Cao Y, Adachi J \& Hasegawa M (1994). Eutherian phylogeny as inferred from mitochondrial DNA sequence data. Jpn J Genet 69: 455472.

14. Yoshikawa S, Shinzawa-Itoh K, Nakashima R, Waono R, Yamashita E, Inoue $\mathrm{N}$, Yao M, Fei MJ, Libeu CP, Mizushima T, Yamaguchi H, Tomizaki $\mathrm{T}$ \& Tsukihara $\mathrm{T}$ (1998). Redox coupled crystal structural changes in bovine heart cytochrome c oxidase. Science 280: 1723-1729.

15. Mustafa G, Tahir A, Asgher M, Rahman MU \& Jamil A (2014). Comparative sequence analysis of citrate synthase and $18 \mathrm{~S}$ ribosomal DNA from a wild and mutant strains of Aspergillus niger with various fungi. Bioinformation 10: 1-7.
16. Yang Z (1996). Maximum-likelihood models for combined analyses of multiple sequence data. $J$ Mol Evol 42: 587-596.

17. Huelsenbeck JP (1995). Performance of phylogenetic methods in simulation. Syst Biol 44: 17-48.

18. Russo CA, Takezaki N \& Nei M (1996). Efficiencies of different genes and different tree-building methods in recovering a known vertebrate phylogeny. Mol Biol Evol 13: 525-536.

19. Wu W, Schmidt TR, Goodman M \& Grossman LI (2000). Molecular evolution of cytochrome $\mathrm{c}$ oxidase subunit $I$ in primates: is there coevolution between mitochondrial and nuclear genomes? Mol Phylogenet Evol 17: 294-304.

20. Ruben J (1995). The evolution of endothermy in mammals and birds: from physiology to fossils. Annu Rev Physiol 57: 69-95.

21. Yonghua $\mathrm{Wu}$, Haifeng Wang (2018). Convergent evolution of bird-mammal shared characteristics for adapting to nocturnality. Proc Royal Soc B 286(1897): 20182185.

22. Pyron RA \& Wiens JJ (2011). A largescale phylogeny of Amphibia including over 2800 species, and a revised classification of extant frogs, salamanders, and caecilians. Mol Phylogenet Evol 61: 543-583.

23. Rose CS (2003). The developmental morphology of salamander skulls. Amphibian Biol 5: 1684-1781.

24. Mustafa G \& Jamil A (2013). Cloning and phylogenetic analysis of an actin encoding DNA fragment from filamentous fungus Trichoderma harzianum. Int J Agric Biol 15: 10131016. 